\title{
A DESIGN GUIDE FOR EARLY-MARKET ELECTROCHROMIC WINDOWS
}

Prepared For:

California Energy Commission

Public Interest Energy Research Program

Prepared By:

Lawrence Berkeley National Laboratory

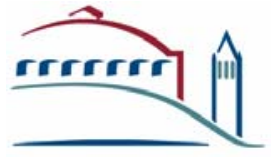

ERNEGT DRLANDD LAWRENCE

BERKELEY NATIONAL LABRRATIRY 


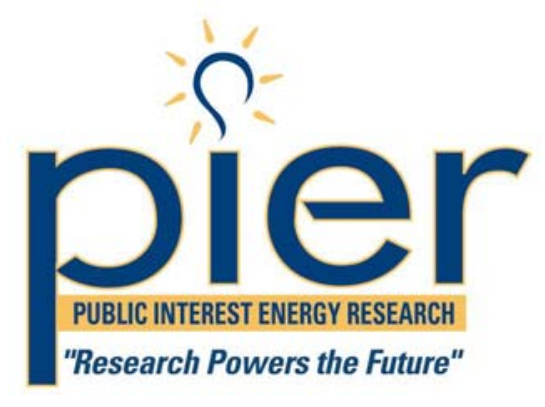

"Research Powers the Future"
Prepared By:

Lawrence Berkeley National Laboratory

Eleanor Lee

Berkeley, California

Contract No. 500-01-023

Prepared For:

California Energy Commission

Public Interest Energy Research (PIER) Program

Chris Scruton

Contract Manager

Ann Peterson

Building End-Use Efficiency Team Leader

Nancy Jenkins

PIER Energy Efficiency Research Office Manager

Martha Krebs, Ph.D.

Deputy Director

ENERGY RESEARCH AND DEVELOPMENT

DIVISION

B. B. Blevins

Executive Director

\section{DISCLAIMER}

This report was prepared as the result of work sponsored by the California Energy Commission. It does not necessarily represent the views of the Energy Commission, its employees or the State of California. The Energy Commission, the State of California, its employees, contractors and subcontractors make no warrant, express or implied, and assume no legal liability for the information in this report; nor does any party represent that the uses of this information will not infringe upon privately owned rights. This report has not been approved or disapproved by the California Energy Commission nor has the California Energy Commission passed upon the accuracy or adequacy of the information in this report. 


\section{Acknowledgments}

This work was supported by the California Energy Commission through its Public Interest Energy Research (PIER) Program on behalf of the citizens of California and by the Assistant Secretary for Energy Efficiency and Renewable Energy, Office of Building Technology, State and Community Programs, Office of Building Research and Standards of the U.S. Department of Energy under Contract No. DE-AC02-05CH11231.

We are indebted to Chris Scruton and Nancy Jenkins of the California Energy Commission and Marc LaFrance of the US Department of Energy for their invaluable guidance, enthusiasm, and support throughout this multiyear project. We would also like to thank the following members of our Project Advisory Committee for taking the time to provide insightful technical and market-related input into the direction of this R\&D:

$\begin{array}{ll}\text { Carl Wagus } & \text { American Architectural Manufacturers Association } \\ \text { Thomas Guarr } & \text { Gentex Corporation } \\ \text { Jan Berman } & \text { Mechoshade Systems, Inc. } \\ \text { Grant Brohard } & \text { Pacific Gas \& Electric Company } \\ \text { Charles Hayes } & \text { SAGE Electrochromics, Inc. } \\ \text { Micheal Myser } & \text { SAGE Electrochromics, Inc. } \\ \text { John Durschinger } & \text { Skidmore, Owings \& Merrill LLP } \\ \text { Gregg Ander } & \text { Southern California Edison } \\ \text { Hula Demiryont } & \text { Sytecorp } \\ \text { Kevin Settlemyre } & \text { The Green Roundtable, Inc. } \\ \text { Glenn Hughes } & \text { The New York Times } \\ \text { David Thurm } & \text { The New York Times } \\ \text { Mark Levi } & \text { US General Services Administration } \\ \text { Thomas Mifflin } & \text { Wausau Window and Wall Systems }\end{array}$

Thomas Mifflin of Wausau Window and Wall Systems provided enthusiastic and dedicated guidance, engineering support, and materials for our electrochromic field test facility's curtainwall system without which this project probably would not have gotten off the ground. SAGE Electrochromics, Inc. also remained dedicated throughout the duration of this project, providing technical assistance and product revisions to meet our demanding project requirements.

The project team consisted of staff from a variety of disciplines within the Environmental Energy Technologies Division at the Lawrence Berkeley National Laboratory:

Andre Anders, Ph.D., Material Scientist, Thin Film Coatings

Zachery Apte, IR Laboratory Tests

Robert Clear, Ph.D., Human Factors, Statistical Analysis

Dennis DiBartolomeo, Systems Engineering, Field Test Operations

Luis Fernandes, Ph.D., Radiance Mathematica Optimizations

Daniel Fuller, Testbed Networking and Communications

Howdy Goudey, IR Laboratory Tests, Curtainwall Engineering, Sensors and Instrumentation Chuck Hambelton, Curtainwall Engineering, Sensors and Instrumentation

Philip Haves, Ph.D., Commercial Building Systems, HVAC Interactions Vorapat Inkarojrit, Ph.D., Human Factors, High-Dynamic-Range Digital Imaging Joseph Klems, Ph.D., Heat Flow Monitoring and Thermal Analysis 
Christian Kohler, Window Modeling, Testbed Networking and Communications

Judy Lai, Radiance Modeling

Eleanor Lee, Co-Principal Investigator

Steve Marsh, Curtainwall Engineering, Sensors and Instrumentation

Robin Mitchell, Window Modeling

Thomas Richardson, Ph.D., Material Scientist, Electrochromics

Micheal Rubin, Ph.D., Material Scientist, NFRC

Francis Rubinstein, Lighting Controls, IBECS Networking and Controls

Stephen Selkowitz, Principal Investigator

Charles Taberski, Facilities Management, Testbed Facility Engineering and Construction

Duo Wang, Data Analysis

Peng Xu, Ph.D., Commercial Building Systems, HVAC Interactions

Mehry Yazdanian, Heat Flow and Data Analysis

And colleagues from other institutions and companies:

Ren Andersen, Ph.D., National Renewable Energy Laboratory

Oyvind Aschehoug, Ph.D., Visiting Professor, Norwegian University of Science and

Technology, Trondheim

Thibaut Falcon, École Nationale des Travaux Publics de l'État, Field Testing and

Instrumentation

Lixing Gu, Ph.D., Florida Solar Energy Center, Testbed Facility Engineering

Aslihan Tavil, Faculty of Architecture, Istanbul Technical University, Turkey

Greg Ward, Anyhere Software, Radiance Mathematica Optimizations, High-Dynamic-Range

Digital Imaging

Citation: Lee, E.S., S.E. Selkowitz, R.D. Clear, D.L. DiBartolomeo, J.H. Klems, L.L. Fernandes, G.J. Ward, V. Inkarojrit, M. Yazdanian. 2006. A Design Guide for Early-Market

Electrochromic Windows. California Energy Commission, PIER. 500-01-023. LBNL-59950. 


\section{Preface}

The Public Interest Energy Research (PIER) Program supports public interest energy research and development that will help improve the quality of life in California by bringing environmentally safe, affordable, and reliable energy services and products to the marketplace.

The PIER Program, managed by the California Energy Commission (Commission), annually awards up to $\$ 62$ million to conduct the most promising public interest energy research by partnering with Research, Development, and Demonstration (RD\&D) organizations, including individuals, businesses, utilities, and public or private research institutions.

PIER funding efforts are focused on the following six RD\&D program areas:

- Buildings End-Use Energy Efficiency

- Industrial/Agricultural/Water End-Use Energy Efficiency

- Renewable Energy

- Environmentally-Preferred Advanced Generation

- Energy-Related Environmental Research

- Energy Systems Integration

What follows is an attachment to the final report for the Advancement of Electrochromic Windows project, Contract Number 500-01-023, conducted by the Lawrence Berkeley National Laboratory, Berkeley, CA. This project contributes to the PIER Building EndUse Energy Efficiency program.

This attachment, "Advancement of Electrochromic Windows: Journal and Technical Reports" (Attachment A-1), provides supplemental information to the project's final report and includes journal and technical reports related to the following three subjects:

- Systems Engineering

- Performance Impacts

- Information Resources

For more information on the PIER Program, please visit the Commission's Web site at: http://www.energy.ca.gov/research/index.html or contact the Commission's Publications Unit at 916-654-5200. 


\begin{abstract}
Switchable variable-tint electrochromic (EC) windows preserve view out while modulating transmitted light, glare, and solar heat gains. Consumers will require objective information on the risks and benefits of this emerging technology as it enters the market in 2006. This guide provides such information and data derived from a wide variety of simulations, laboratory tests, and a 2.5-year field test of prototype large-area EC windows evaluated under outdoor sun and sky conditions.

This design guide is provided to architects, engineers, building owners, and others interested in electrochromic windows. The design guide provides basic information about what is an electrochromic window, what it looks like, how fast does it switch, and what current product offerings are. The guide also provides information on performance benefits if more mature product offerings were available.

The guide is part of a set of attachments to the "Advancement of Electrochromic Windows: Journal and Technical Reports" document, produced by the Advancement of Electrochromic Windows project, funded by the California Energy Commission's Public Interest Energy Research (PIER) Program and the U.S. Department of Energy. See the CEC PIER website for more information about this project or visit:

http://windows.lbl.gov/comm_perf/Electrochromic/electroSys-cec.htm
\end{abstract}

which duplicates the design guide material on the website and provides visitors with access to all related technical reports. 


\section{Table of Contents}

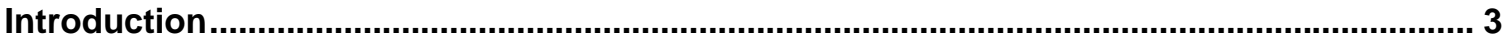

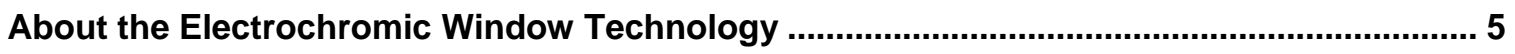

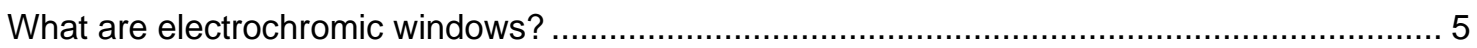

What types of switchable windows are there and what is their commercial status? ................. 6

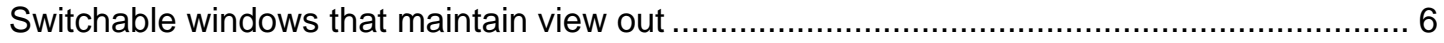

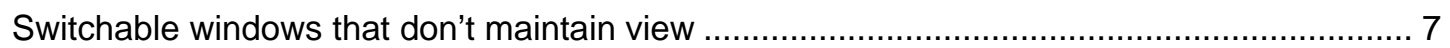

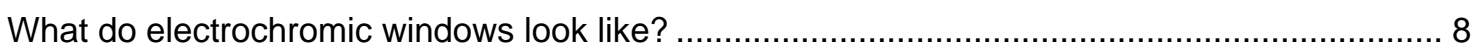

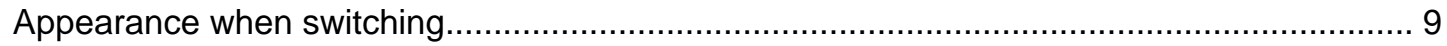

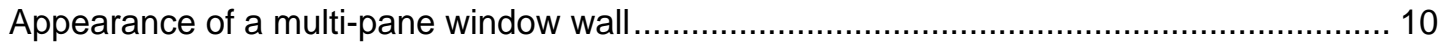

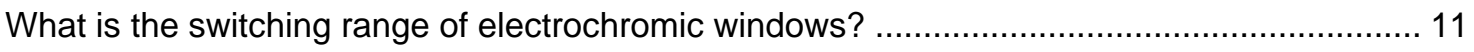

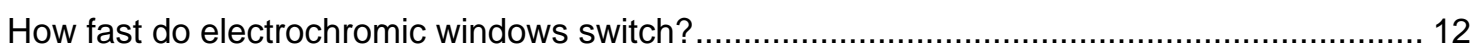

Under what temperatures will electrochromic windows operate? ......................................... 13

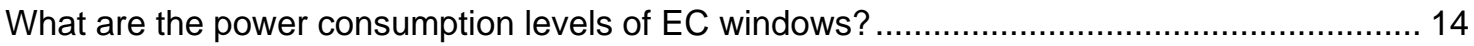

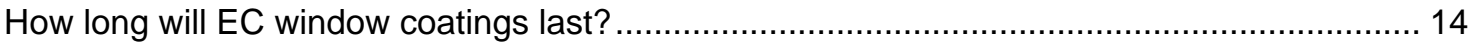

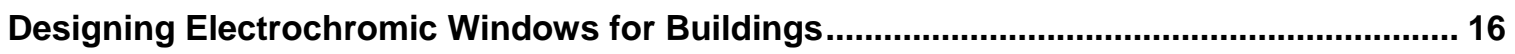

What are the basic components that make up an electrochromic window? ........................... 16

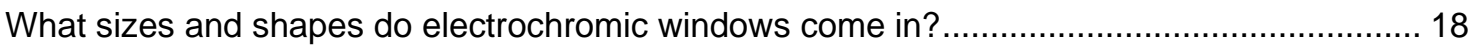

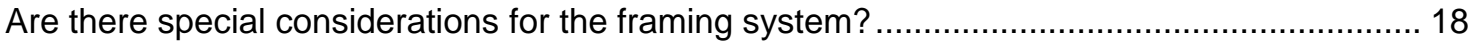

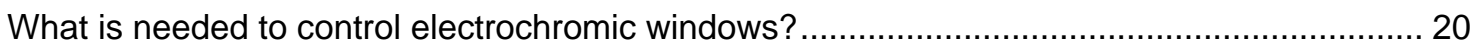

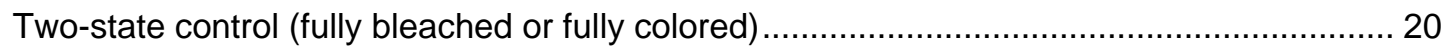

Intermediate-state control (fully bleached, fully colored, and levels of tint in-between)......... 22

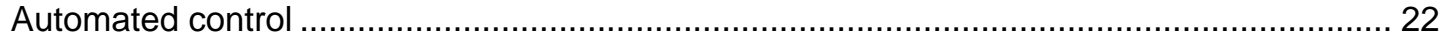

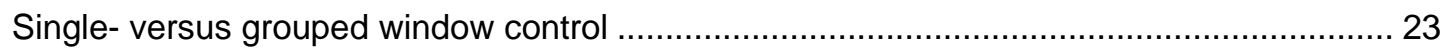

Do EC windows need to be commissioned after installation? ............................................. 24

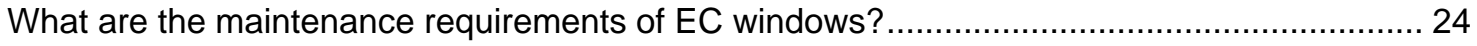

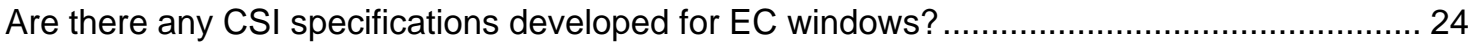

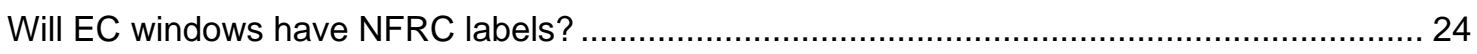

How are dynamic windows accommodated in Title-24 and ASHRAE 90.1? .......................... 25

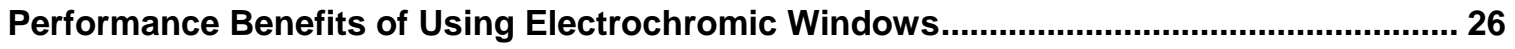

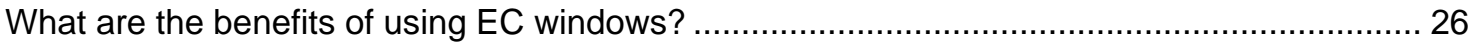

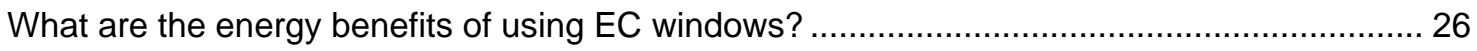

What peak demand reductions can be expected from EC windows? ...................................... 28

What HVAC capacity reductions can be expected from EC windows? ................................... 30

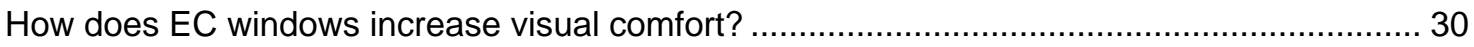

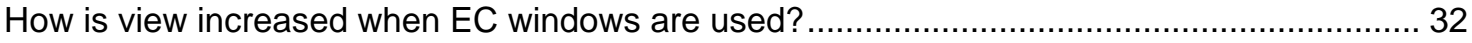


How does one compute the energy savings benefit of EC windows? ................................... 33

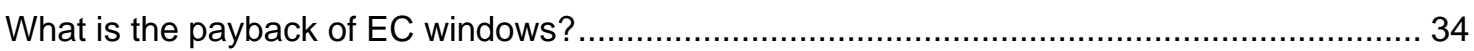

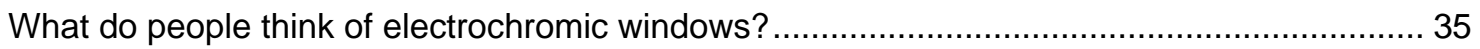

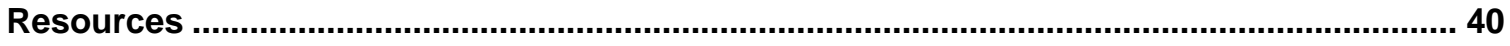

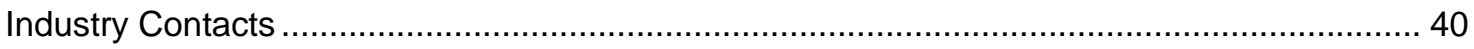

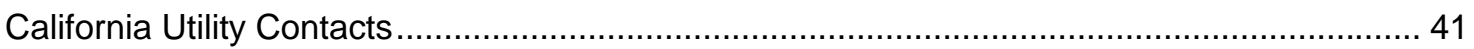

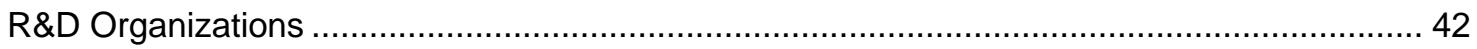

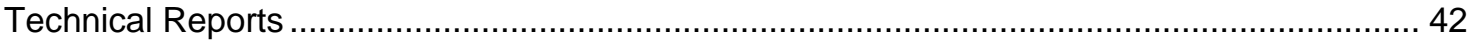

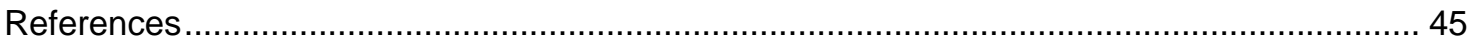

Appendix: Curtainwall Details for an Electrochromic Window Wall ....................................... 46 


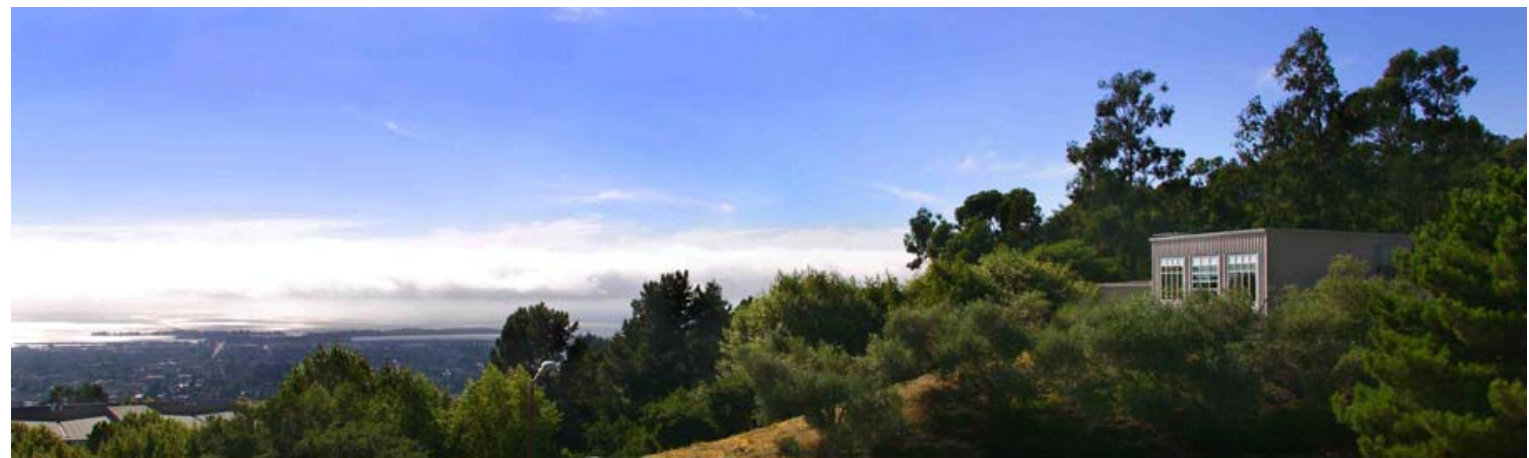

\title{
Advancement of Electrochromic Windows
}

\author{
Building Technologies Program, Environmental Energy Technologies Division \\ Lawrence Berkeley National Laboratory, University of California, Berkeley
}

\section{Introduction}

This guide provides consumer-oriented information about switchable electrochromic (EC) windows. Electrochromic windows change tint with a small applied voltage, providing building owners and occupants with the option to have clear or tinted windows at any time, irrespective of whether it's sunny or cloudy. EC windows can be manually or automatically controlled based on daylight, solar heat gain, glare, view, energy-efficiency, peak electricity demand response, or other criteria. Window controls can be integrated with other building systems, such as lighting and heating/cooling mechanical systems, to optimize interior environmental conditions, occupant comfort, and energy-efficiency.

This new technology is just entering the commercial market. To answer common consumer questions concerning this technology, this guide provides information on:

- What are electrochromic windows?

What do they look like, how fast do they switch, under what temperature conditions do they operate, what is their switching range?

- How does one design electrochromic windows for buildings?

What sizes and shapes do they come in, how are they specified, how does one wire and control the window?

- What are the benefits of using electrochromic windows?

How does one control the windows to obtain energy savings, how does one estimate energy benefits, what is the cost-benefit payback, what do people think of these windows? 
The information and data presented in this guide were derived from a three-year Lawrence Berkeley National Laboratory (LBNL) field study of early-market electrochromic windows completed in the Spring of 2006 (see the "Resources" section for more information). Although currently this guide content focuses on tungsten-oxide EC windows with on-off control (fully bleached and fully colored states only) such as those now being offered by SAGE Electrochromics, Inc., results from the LBNL field study data for EC windows with intermediate state control (variable tint between fully colored and fully bleached) will be relevant as new product offerings become commercially available. Products from other manufacturers may also enter the market in the next few years.

This work was supported by the California Energy Commission through its Public Interest Energy Research (PIER) Program and by the U.S. Department of Energy. 


\section{About the Electrochromic Window Technology}

\section{What are electrochromic windows?}
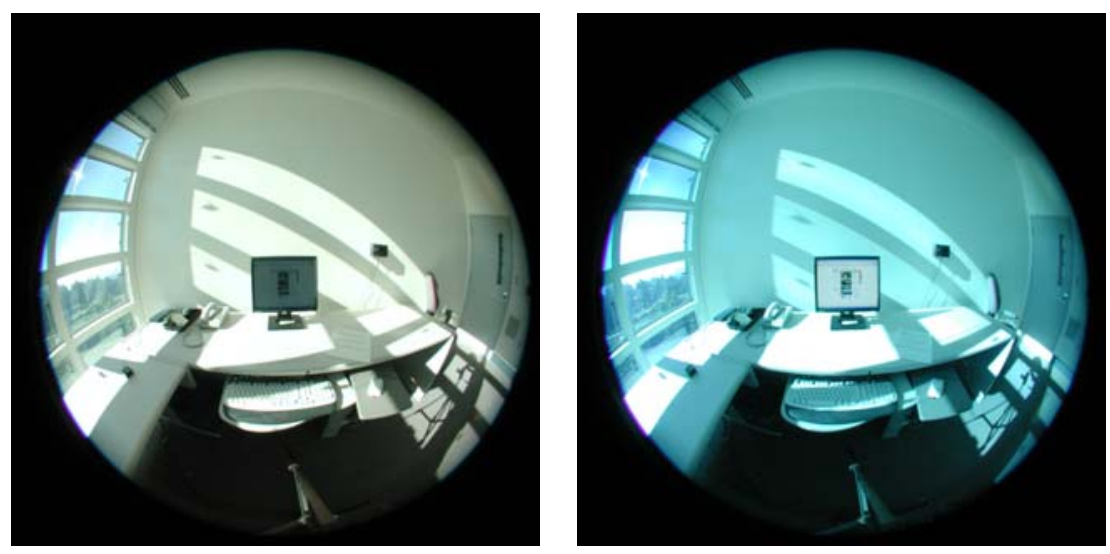

Figure 1. Electrochromic windows in a bleached state (left) or colored state (right).

Electrochromic coatings (EC) are switchable thin-film coatings applied to glass or plastic that can change appearance reversibly from a clear to a dark Prussian Blue tint when a small DC voltage is applied. EC windows preserve the outward view while modulating transmitted light, glare and solar heat gains (Figure 1).

An EC coating is a nanometer-thick $\left(1 \times 10^{-9} \mathrm{~m}, 4 \times 10^{-8}\right.$ inch), multi-layer film or stack deposited on a glass or plastic (Figure 2). Transparent conductors form the outer layers of the stack, an active electrochromic and passive counter-electrode layer form the middle layers, and an ion-conducting electrolyte layer forms the center portion of the stack. The system works like a battery. A bipolar potential is applied to the outer transparent conductors, which causes lithium ions to migrate across the ion-conducting layer from the counter-electrode layer to the electrochromic layer. A reversible electrochemical reaction takes place causing a tinted Prussian Blue appearance. Reversing the potential causes the ions to migrate back, causing a bleached clear appearance.

The material and physical composition of the EC window can vary and these dictate the unique properties of the EC window: its switching range, speed versus temperature characteristics, power consumption when being switched, durability, and color. 

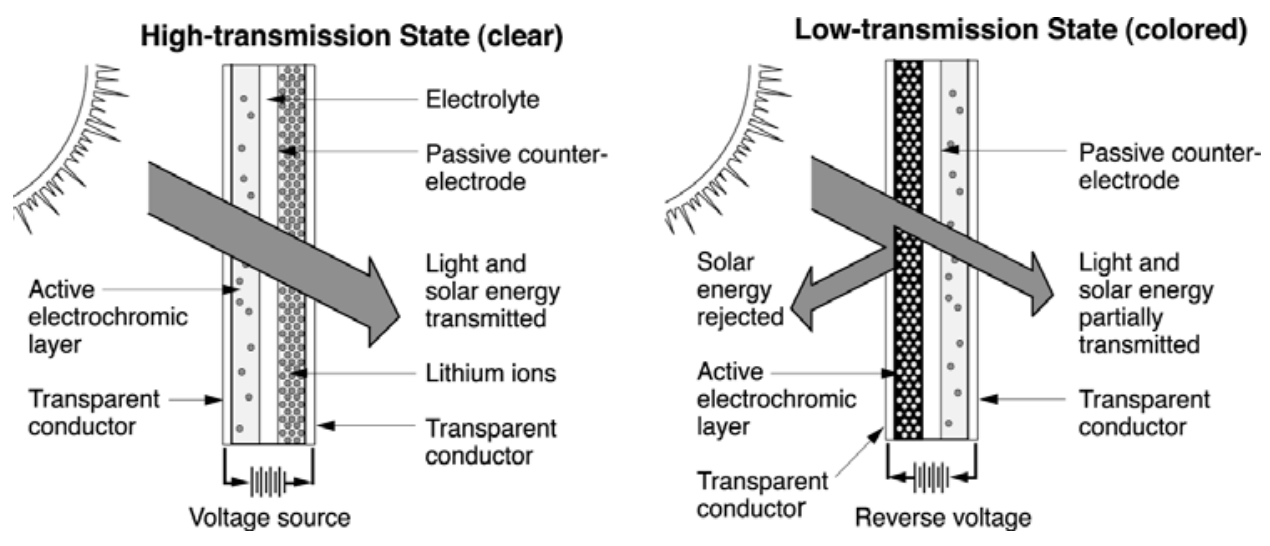

Figure 2. Diagram of a typical tungsten-oxide electrochromic coating.

The reaction that takes place can be grossly simplified [Grandqvist 2000] as follows:

$\mathrm{WO}_{3}+\mathrm{xM}^{+}+\mathrm{xe} \mathrm{e}^{-} \leftrightarrow \mathrm{M}_{\mathrm{x}} \mathrm{WO}_{3}$

with $\mathrm{M}^{+}=\mathrm{H}^{+}, \mathrm{Li}^{+}, \mathrm{Na}^{+}$or $\mathrm{K}^{+}$, and e- denoting electrons.

For more about the material science of EC window coatings, see:

http://windows.lbl.gov/materials/chromogenics/default.htm

\section{What types of switchable windows are there and what is their commercial status?}

\section{Switchable windows that maintain view out}

- Electrochromic windows (described in the previous section) are the most promising switchable window of today. The main advantages are that they are efficient at rejecting solar heat gains and admitting daylight, require low-voltage power to switch, can require no power to maintain the EC in any switched state for several days (depending on material composition), and preserve a clear view out. Independent tests have indicated that electrochromic windows can have long-term durability.

- Photochromic materials slowly change their tint in response to light intensity. They are used in eyeglasses that change from a clear appearance when indoors to a tinted appearance when in the bright outdoors. Large photochromic windows are not commercially available.

- Suspended particle device (SPD) windows switch instantly from a dark blue to a clear slightly hazy state with an applied AC voltage. When unpowered, the window is tinted. 
When powered (100 V AC or $0.05-0.5 \mathrm{~W} / \mathrm{ft}^{2}$ of glass), the window can be set to any intermediate state between clear and fully colored. The SPD window is laminated, can be fabricated in up to $4 \times 8$ feet sheets, and is offered in curved and flat shapes. Long-term durability (e.g., greater than 3-5 years) has not been independently verified so this window type is not promoted in this guide. This product is commercially available (e.g., ThermoView AlterLite windows).

\section{Switchable windows that don't maintain view}

- Thermochromic materials slowly change from a clear state when cold to a more diffuse, white translucent state when hot. Prototype windows have been tested but are not commercially available.

- Liquid crystal device windows are translucent when in an unpowered state and become instantly clear (with a noticeable haze) when power is applied. Power must be applied continuously for the window to remain clear (24-100 V AC or $0.5 \mathrm{~W} / \mathrm{ft}^{2}$ of glass). The window has a high daylight and solar heat gain transmittance and is therefore of limited use in commercial buildings. The window is commercially available. While typically used for highend interior applications, ultraviolet (UV)-stable formulations now permit exterior applications but the cost remains high.

- Reflective hydride window coatings are a relatively new type of electrochromic device that switches from a transparent to a reflective appearance with the injection of hydrogen gas. This coating is still in the R\&D stage. More information can be found at: http://windows.lbl.gov/materials/chromogenics/default.htm

This guide focuses on tungsten-oxide $\left(\mathrm{WO}_{3}\right) \mathrm{EC}$ windows such as that produced by SAGE Electrochromics, Inc. At the time this guide was produced (Spring 2006), this type of EC window was only just introduced by SAGE Electrochromics, Inc. (an all solid state lithium based $\mathrm{WO}_{3}$ device) to the commercial market in sizes of up to 42.5 by 60 inches with on-off control (fully bleached and fully colored states only). Products from other manufacturers may enter the market shortly. An EC window product was offered in Germany by Flabeg GmbH \& Co. (polymerlaminated $\mathrm{WO}_{3}$ device) in 1997 in sizes up to approximately 3x6 feet with intermediate-state controls (ability to modulate the EC window to any tinted state) but is no longer available (for unknown reasons). 


\section{What do electrochromic windows look like?}

The EC window tint varies from a clear to a deep Prussian Blue. At any switched state, EC windows provide an undistorted view out with no haze. From the exterior, the clear state can look slightly yellow to green under dim conditions (depending on EC type and age), while the darkest tinted state can look almost like a black spandrel panel under bright conditions. Early-market prototypes were tested in the field (Figures 3-4 below) and these exhibited a slight pink to yellowish non-uniform reflectance. There were also a few minute pinholes (stays clear when switched). These colors and non-uniformity are not expected to occur with commercially available products (e.g., new SAGE windows will switch from a slight clear green to dark blue).

The EC window is sold as a dual-pane insulating glass unit (IGU). In the following photographs, the IGU was composed of two clear glass window layers with the EC coating on the inside surface of the exterior layer (\#2 surface).
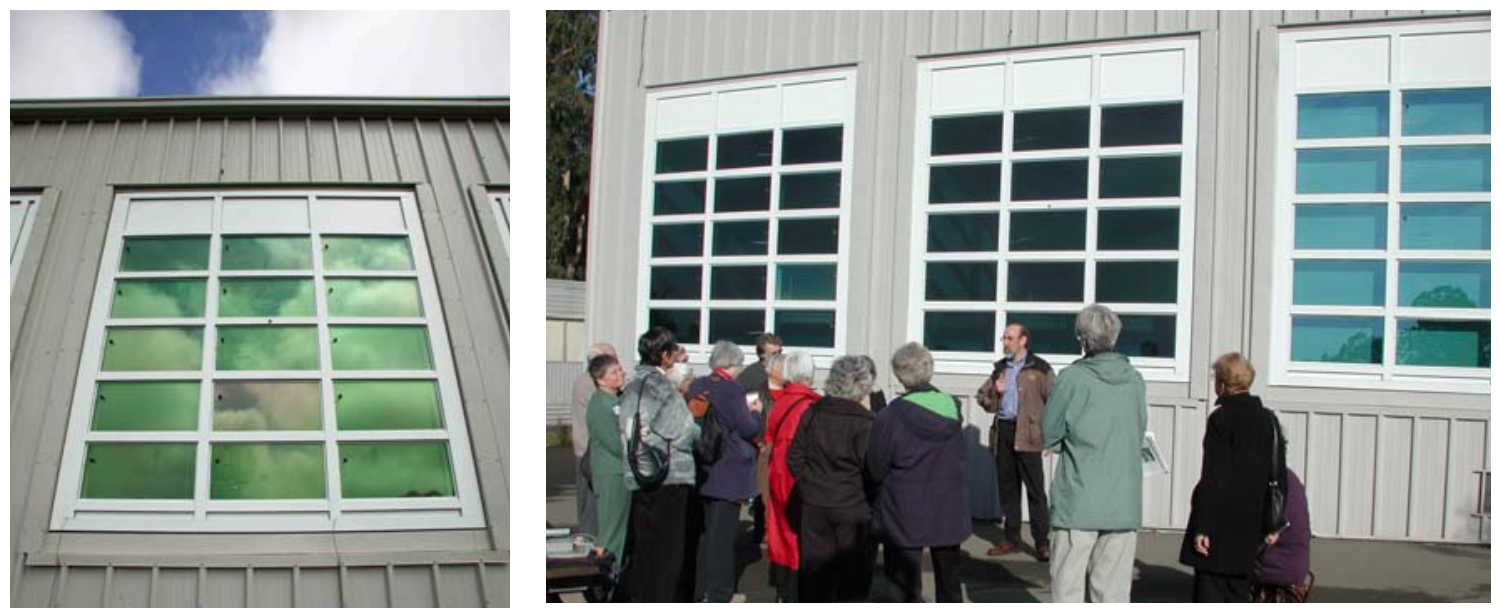

Figure 3. Exterior views of prototype EC windows at the fully tinted state (left and right photos) and a conventional spectrally-selective Azurlite window with interior Venetian blinds on the far right. 

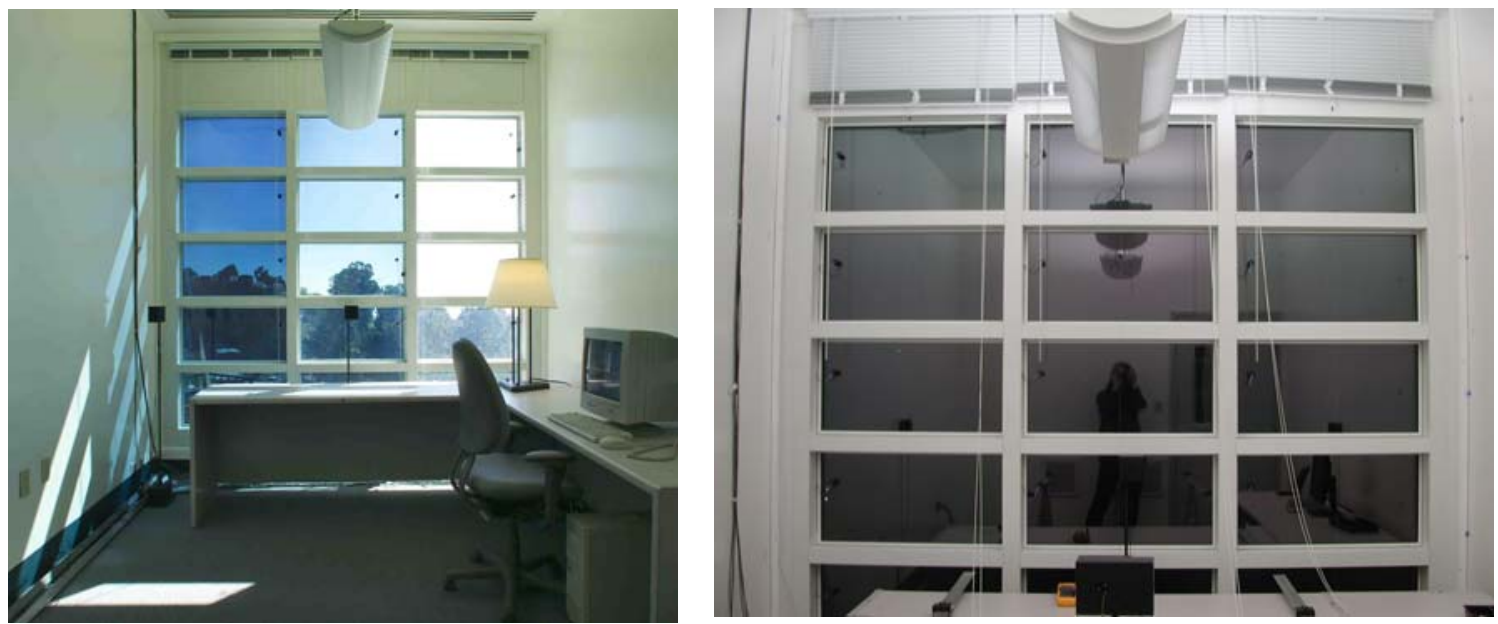

Figure 4. Interior views of the EC window wall with a) EC window at darkest, intermediate, and clearest states during the day (left) and b) EC window at its darkest state at night (right). The LBNL-installed sensors on the glass are not part of the EC product.

\section{Appearance when switching}

When the EC window is not being switched ("at rest"), the window tint is uniform across the IGU. When the $\mathrm{EC}$ window is in the process of being switched, the window tint is non-uniform. The edges where the bus bars are located switch faster than the center of the window (Figure 5).

a

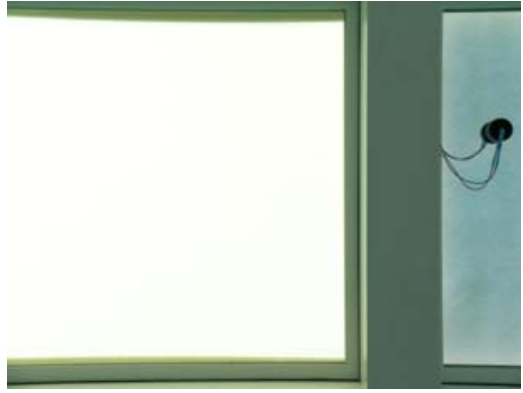

C

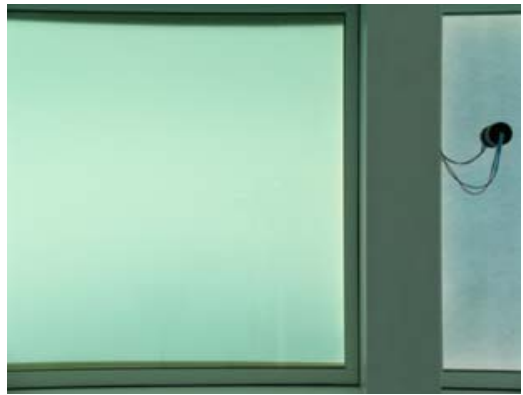

b

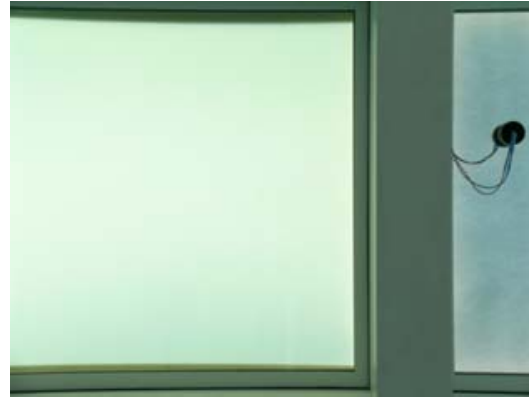

d

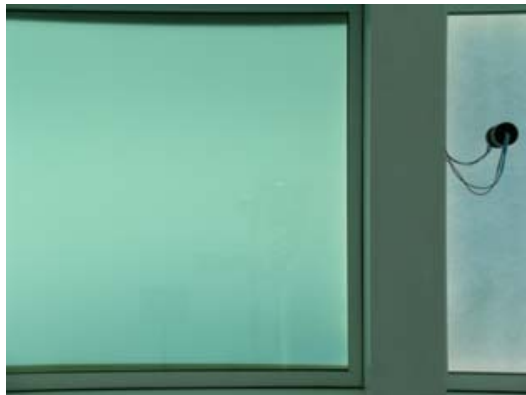

Figure 5. Appearance of the EC window when switching from clear (a) to tinted (d). The bus bars are located on the top and bottom edges so the tinting occurs faster at these edges while the middle portion is tinted more slowly. When switched in the reverse direction, the edges bleach more quickly while the middle portion clears more slowly. 
Note: Electrical potential is applied to thin metal strips located at opposite edges of the IGU and these are called "bus bars".

\section{Appearance of a multi-pane window wall}

When a window wall is composed of multiple, immediately adjacent EC windows, color matching is important for the aesthetics of the facade. If adjacent EC windows do not match, the façade can have a slight to noticeable checkerboard appearance.

One manufacturer produced a control system that enables between-window color matching at not only the end states (fully bleached or tinted) but also at any intermediate tinted state (this product is no longer commercially available). Other manufacturers are working to develop such capabilities. Color matching could drift over time and may need to be corrected slightly with software adjustments every few years, depending on how the manufacturer has implemented transmittance control.

When switching, the tint of side-by-side EC windows may not match because the rate of switching is dependent on the surface temperature of the EC window and these could differ if some window units are shaded while others are not (e.g., window with an overhang). If different size window units are used, the larger units will switch slower than the smaller units.
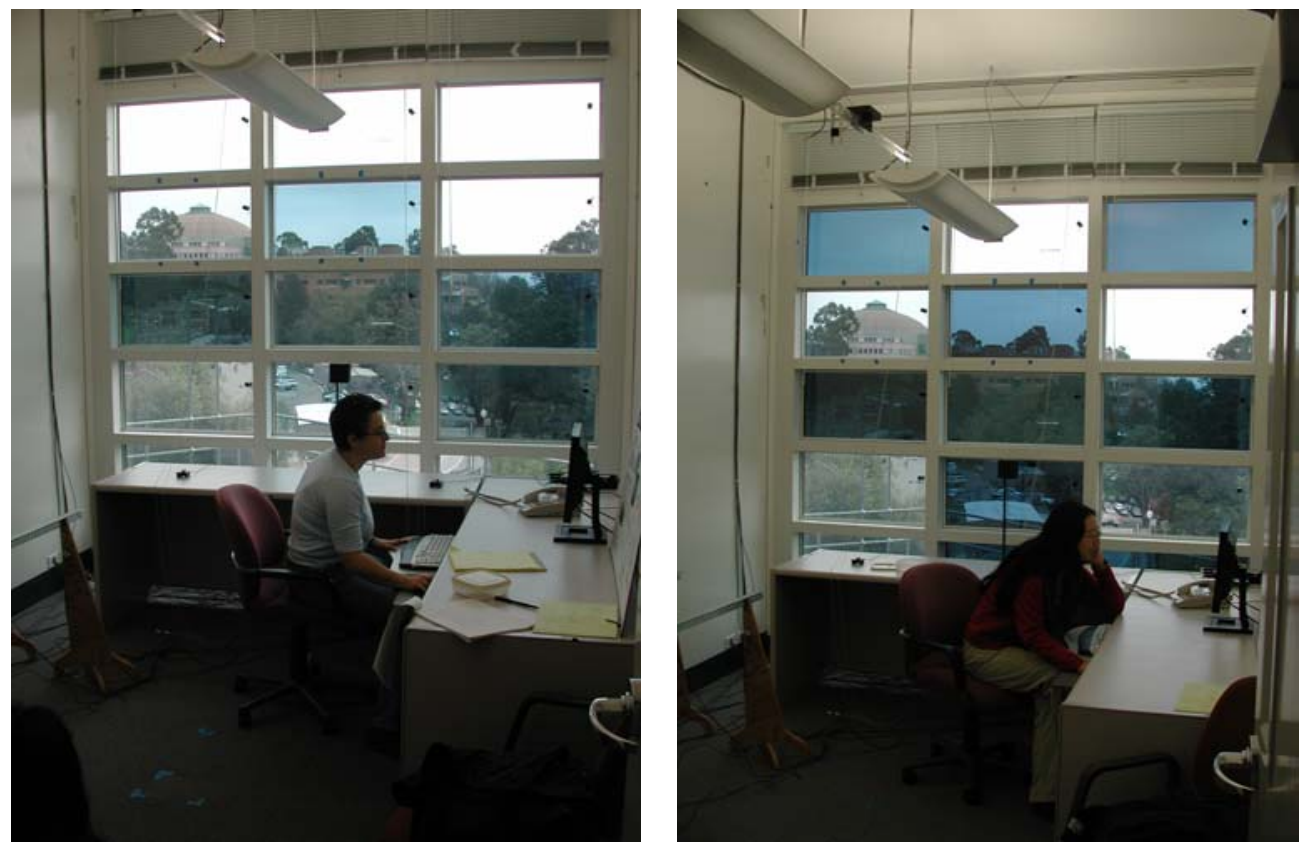

Figure 6. In a field test, occupants were provided with a web-based dimmer or slider switch so that they could manually switch individual EC windows to any transmittance level between fully clear and fully tinted. Occupants switched some EC windows for privacy, glare control, daylight, and view. 
Given individual pane control, patterns of various tint levels could be deliberately created by the occupants or the architect in response to dynamic conditions (Figure 6) or other control criteria (signage, etc.).

\section{What is the switching range of electrochromic windows?}

The visible transmittance (TV) and solar heat gain coefficient (SHGC) range of EC coatings vary depending on the material composition. U-factor is not affected by the change in tint. Generally, the wider the switching range, the more control one has under variable sun and sky conditions:

- A high-transmittance clear state lets in more daylight when it is overcast or early morning or late afternoon.

- A dark-transmittance colored state reduces interior window and surface brightness that can cause visual discomfort. A transmittance of less than $T v<0.001$ is needed to reduce the brightness of the sun orb down to comfortable levels.

- Generally, commercial buildings in the U.S. tend to be internally-load dominated buildings due to their high occupant and equipment density and operate in a cooling mode even during the winter. For these types of buildings, the SHGC range should be as low as possible compared to the Tv range.

- Whether the windows are small or large, a wide switching range is important.

The EC window is sold as a dual-pane insulating glass unit (IGU) where the EC coating is applied to the inside surface of the exterior glazing layer. The window's overall switching range is determined not only by the EC coating but also the glass layers of the IGU. The exterior glazing layer (or substrate) itself can be tinted or clear. The interior glazing layer can be any type of glass (tinted, low-e coated, fritted, etc.). An example of center-of-glass EC window properties if both layers of the IGU are clear glass is as follows:

- $\mathrm{Tv}=0.60-0.05$

- $\mathrm{SHGC}=0.48-0.09$

- U-factor=1.59-1.87 W/m ${ }^{2}{ }^{\circ} \mathrm{C}\left(0.28-0.33 \mathrm{Btu} / \mathrm{h}-\mathrm{ft}^{2}-{ }^{\circ} \mathrm{F}\right)$ with $90 \%$-argon or air fill, respectively. The U-factor stays constant irrespective of switching level.

- The emittance of the EC glazing layer was assumed to be 0.84 on the exterior uncoated surface and 0.15 on the interior coated surface.

Switching ranges can be computed using the WINDOW5 software and spectral data. See more about EC window system design in the section "Design". 


\section{How fast do electrochromic windows switch?}

Switching speed varies with the size and exterior surface temperature of the EC window (which is dictated by incident solar radiation levels, wind speed, and air temperature):

- If the window area is small, the EC will switch faster because the distance between the bus bars is small. For example, for an18-inch distance between bus bars, the fastest switching time is between 1-4 minutes under sunny and/or hot conditions.

- For larger windows, switching time can be significantly longer. Faster switching of large-area EC glass is achieved by applying additional thin conductor line(s), thus allowing for faster distribution of the electrical current over the EC pane. An additional conductor also allows for the possibility of independent control of segments within a larger pane offering the potential for implementing more optimal daylighting strategies. Larger EC panes with additional conductors are offered by SAGE Electrochromics, Inc.

- If the window is hot due to high ambient air temperatures and/or because sunlight is striking the facade, the EC will switch faster. When tinted, the EC absorbs solar radiation, which then raises its surface temperature and increases switching speeds. Under cold conditions when solar radiation levels are low (e.g., early morning or cloudy sky conditions), the EC can take a long time to switch from fully bleached to fully colored.

- When switching from clear to fully tinted, speeds are fast in the beginning, then slower toward the end (Figure 7). If cold, the EC can switch approximately $80 \%$ of its full switching range quickly, then take a long time to reach the last approximately $20 \%$ of full tinting (i.e., exponential function). For example, for an 35x18-inch tungsten-oxide EC window, these switching times were measured in the field (18-inch distance between bus bars):

- When the EC surface temperature is greater than approximately $10^{\circ} \mathrm{C}\left(50^{\circ} \mathrm{F}\right)$, switching speeds are less than 6-7 minutes. Under sunny, warm conditions, switching speeds can be less than 4 minutes.

- If the EC surface temperature is between $-3^{\circ} \mathrm{C}$ to $-1^{\circ} \mathrm{C}\left(27-30^{\circ} \mathrm{F}\right)$, it can take 37 minutes to color or bleach between a visible transmittance (Tv) of $\mathrm{Tv}=0.56$ and $\mathrm{Tv}=0.13$ (Figure 7). It can take even longer to get down to its minimum transmittance ( $T v=0.05)$. The lower transmittance, darker tint levels are useful if the EC window is being used to control window glare and direct sun. With low switching speeds, occupants will most likely need to resort to using interior blinds to block low angle direct sun from their field of view. 


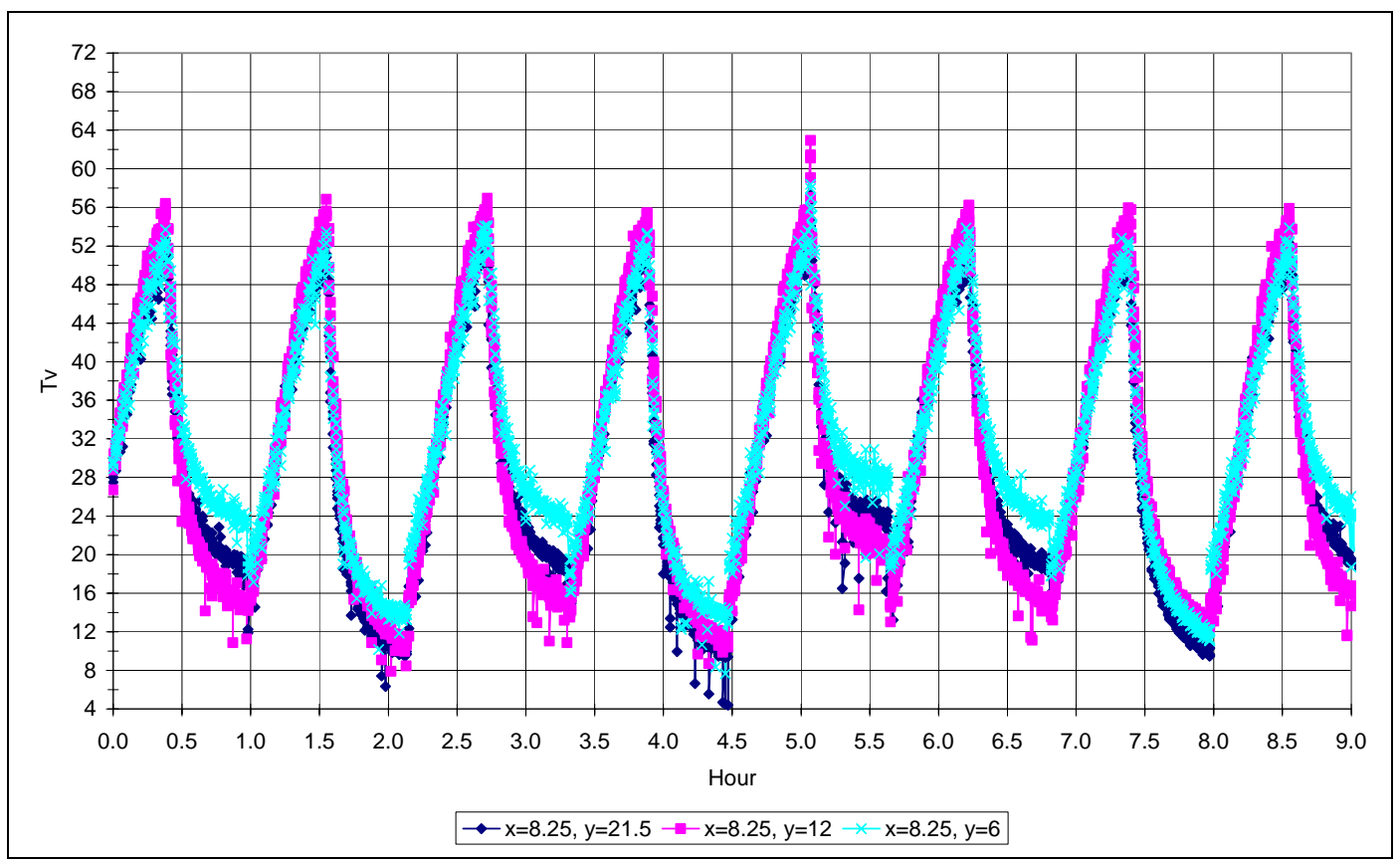

Figure 7. EC transmittance versus time, or switching speed of a 35x18-inch device (18-inch between bus bars) with an average EC surface temperature of $-3^{\circ} \mathrm{C}\left(27^{\circ} \mathrm{F}\right)$. Each transmittance sensor was $0.21 \mathrm{~m}$ ( $x=8.25$ inches) from the bus bar edge but at various distances from the non-bus-bar edge ( $y$ dimension in legend (inches)). Transmittance levels are not expected to match when in the process of switching.

\section{Under what temperatures will electrochromic windows operate?}

LBNL and NREL have cycled EC windows between bleached and colored states within a surface temperature range of $-10^{\circ} \mathrm{C}$ to $95^{\circ} \mathrm{C}\left(14-203^{\circ} \mathrm{F}\right)$. EC switching speeds slow down considerably at the lower temperatures as noted above.

In terms of actual operating conditions, the surface temperature of $\mathrm{EC}$ windows will not reach levels of $95^{\circ} \mathrm{C}\left(203^{\circ} \mathrm{F}\right)$ in typical vertical window and skylight applications. SAGE

Electrochromics, Inc. monitored EC surface temperatures of up to $76^{\circ} \mathrm{C}$ in various outdoor applications (Arizona desert, sloped skylights facing south, etc.). LBNL measured exterior glass surface temperatures for an EC IGU with clear glass substrates of up to $65^{\circ} \mathrm{C}$ on sunny days for a south-facing vertical EC window in Berkeley, California.

The exterior surface temperature of EC windows can get quite hot because the EC window absorbs solar radiation when it's tinted. With a low-e coating and insulating glass unit composition, the interior surface temperature of the window can be near ambient room air temperatures. Exact values can be computed using the WINDOW5 software. Without a low-e coating, EC windows could cause considerable thermal discomfort. 


\section{What are the power consumption levels of EC windows?}

Low-voltage power is required to switch EC windows and for some types of windows, a small applied voltage is needed to keep the EC in a constant state, irrespective of the level of tint. For example:

- The polymer laminated $\mathrm{WO}_{3} \mathrm{EC}$ window requires power only when switching the $\mathrm{EC}$ window to a different level of tint; without power, the EC tint remains at the same level of tint for several days.

- SAGE Electrochromic's window requires constant power - the following are monitored power consumption levels (end use power at the wall outlet) for an array of (15) 35x18 inch windows tested in the field (18-inch distance between bus bars); power levels are likely to scale with window area:

- If no power is applied, the EC window "rests" at the clear state. The level of tint at the clear state will vary slightly between windows (e.g., $\mathrm{Tv}=0.60-0.70)$ and may be discernable when comparing two side-by-side windows. The EC window can be left unpowered during the night.

- If the EC window is in the process of being switched, peak power consumption is 0.26 $0.32 \mathrm{~W} / \mathrm{ft}^{2}$-glazing (5-6 W for a 42.5x60 inch EC window).

- If the EC is being held constant at any level of tint, steady-state power consumption is 0.07-0.15 W/ft ${ }^{2}$-glazing (1.2-2.6 W for a 42.5x60 inch window), assuming a 1-to-1 relationship between the EC window unit and its window controller. This includes power to the window, electronic circuitry for control, and parasitic losses due to the efficiency of the power supply.

- Average daily power consumption of the EC system (window+controller+power supply) during a 12-hour day was monitored to be the same as steady-state power levels in the bullet above. These consumption levels can be reduced to $25-30 \%$ of current levels, if the control circuitry and power source are designed more efficiently.

\section{How long will EC window coatings last?}

Long-term EC window durability has been evaluated by the National Renewable Energy Laboratory (NREL) under steady state environmental conditions defined by the ASTM Standard E2141-02. The ASTM standard requires that the EC window be cycled between its maximum visible (photopic) transmittance and at least one-fourth of the maximum transmittance state while the EC windows are irradiated with a minimum of a 1.0 UV-sun equivalent (of an AM 1.5 global solar spectrum) under controlled conditions (elevated temperature of $85^{\circ} \mathrm{C}\left(185^{\circ} \mathrm{F}\right)$ ). NREL has successfully cycled SAGE EC windows between maximum and one-fifth of the maximum state 
(e.g., Tv=0.60-0.12) for over many tens of thousands of cycles. Long-term durability has not yet been assessed by a third party under outdoor field conditions where the EC window is cycled between maximum bleached and colored states (e.g., Tv=0.60-0.05).

EC window coatings are somewhat analogous to batteries. Over time, one may lose a small fraction of the full switching range of the $\mathrm{EC}$ window or it can develop catastrophic cosmetic defects. It is unknown what factors contribute to acceleration of degradation. Using the ASTM Standard E2141-02, NREL has cycled some EC windows between bleached and colored states for tens of thousands of cycles (full bleach to full color then back again) and has measured no significant loss in the switching range of the EC window, nor any cosmetic deterioration.

For more information on electrochromic window durability, see http://www.nrel.gov/buildings/windows/durability.html 


\section{Designing Electrochromic Windows for Buildings}

\section{What are the basic components that make up an electrochromic window?}

Note in the "About the Electrochromic Window Technology" section, the terms "window" and "insulating glass unit" are used rather loosely. An electrochromic window, to be specific, is composed of an insulating glass unit (IGU) and window frame. The EC insulating glass unit (Figure 8) is composed of two panes or layers of glass assembled with a spacer, then sealed on all four edges, where the exterior glass layer has the EC coating on the second, \#2 interior-facing surface (glass surfaces of a window are numbered from the exterior to interior). The following describes what is feasible with EC IGUs, not necessarily what is commercially available at this time:

- The exterior layer of glass (or "substrate" on which the EC coating is deposited) can be tinted. If this substrate is heavily tinted, the tint plus EC coating at its tinted switched state will increase thermal stress and the likelihood of glass breakage.

- The exterior substrate can have a surface treatment (e.g., frit) on the exterior \#1 surface but not on the interior \#2 surface with the EC coating.

- The exterior substrate can be of any type of glass (e.g., laminated, tempered, heatstrengthened, etc.), but it will most likely be tempered or heat-strengthened because the $\mathrm{EC}$ in its tinted state increases thermal stress. Lamination is possible, but lamination will eliminate the low-e properties of the EC coating (if it has such properties).

- The exterior glazing layer will have metallic printed bus bars located on two parallel edges. A 2-conductor wire will extend from this edge and terminate in a 2-pin pigtail connector (approximately 5 to 10 inches in length).

- The interior layer of glass can be any type of glass. If the EC coating does not have lowemittance properties (e.g., e $\leq 0.15$ ), then the interior layer should have a low-e coating. For the IGU assembly, the low-e coating should be on the \#3 surface to reduce heat transfer to the interior.

- Gas fill between the two panes can be of any type of gas fill; i.e., air or an inert gas such as argon or krypton.

- Spacers should be insulated to prevent thermal conduction and condensation.

- A proper edge seal is important. EC coatings degrade rapidly if water vapor is allowed to enter into the between-pane air gap. The IGU industry is mature, so seal failure is rare and unlikely to occur, according to industry experts. 


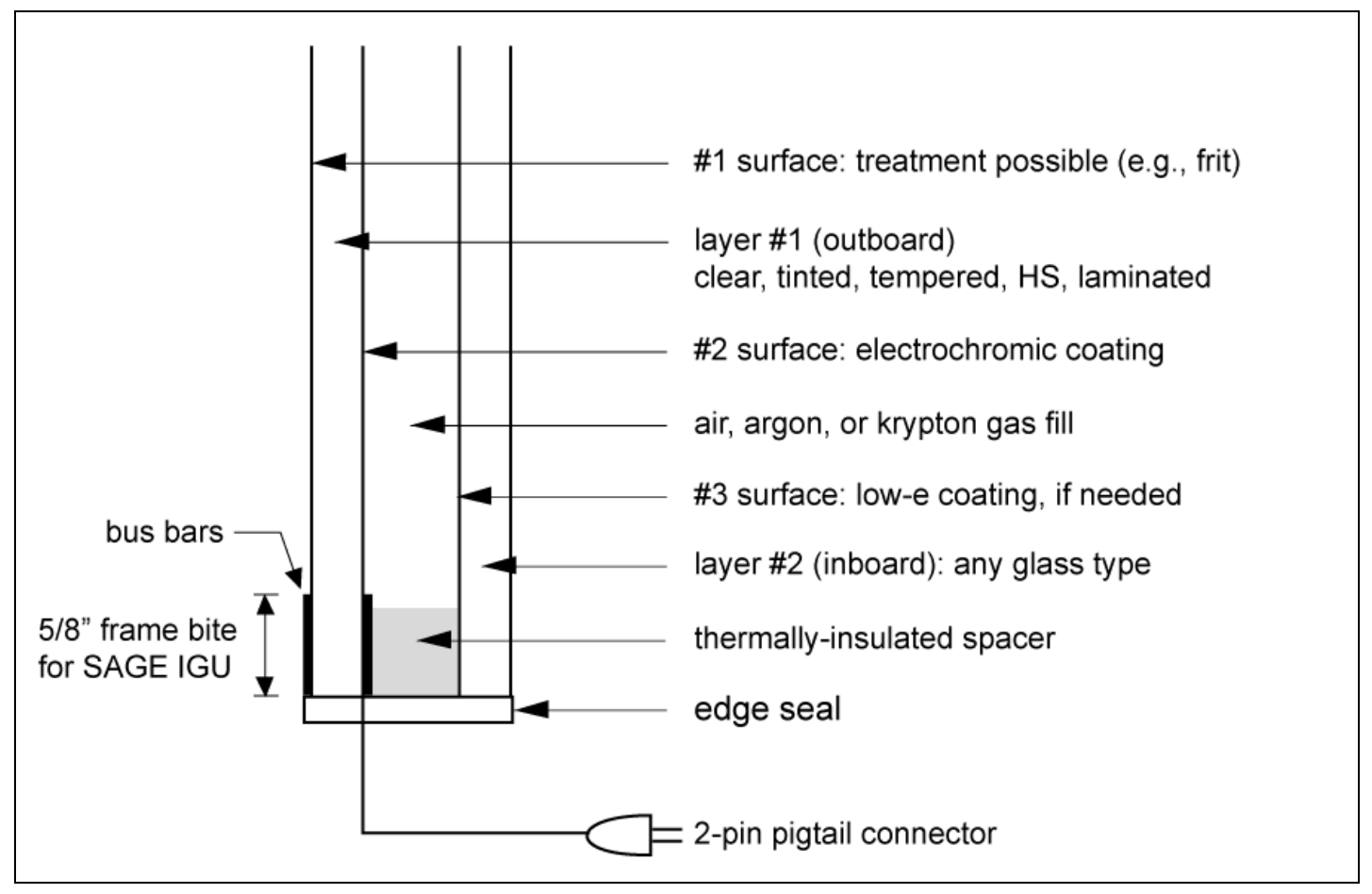

Figure 8. Diagram of a typical electrochromic insulating glass unit.

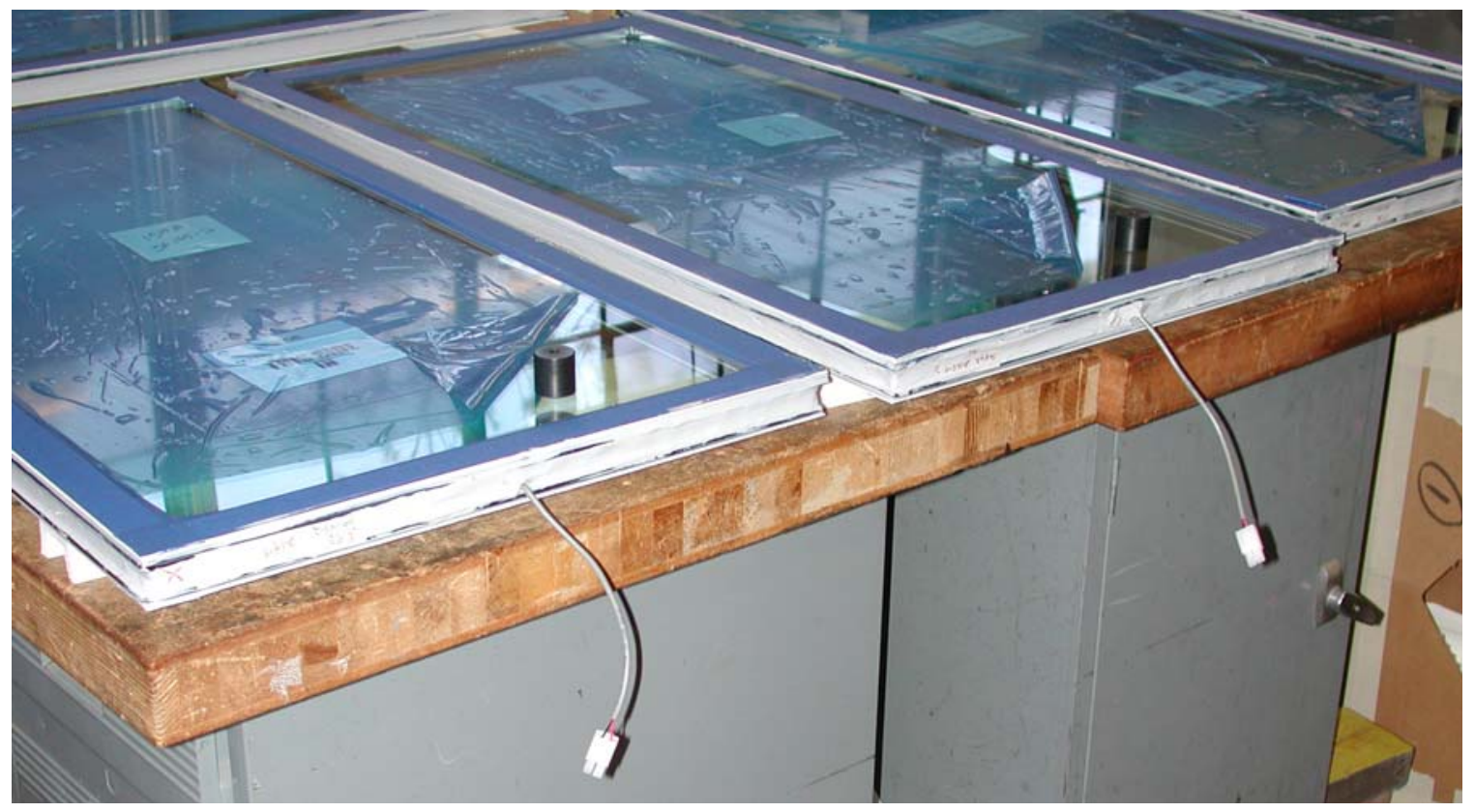

Figure 9. Photograph of typical electrochromic insulating glass units with pigtail connector coming out of one edge of the IGU. The actual 2-pin connector head can be made smaller and waterproofed. 


\section{What sizes and shapes do electrochromic windows come in?}

Emerging EC window products are likely to come in limited sizes and shapes in order to keep costs down. EC windows are available in flat rectangular shapes. Flat, irregular shapes could be produced but are likely to be very costly.

At present, SAGE Electrochromics, Inc. is the only supplier of electrochromic insulating glasss units (see Resources/ Industry Contacts). They supply insulating glass units in sizes of up to 42.5 by 60 inches for skylight and window applications.

EC glass cannot be cut then installed in window frames in the field (as one can do with monolithic clear glass, for example). EC glass must be part of a sealed insulating glass unit assembly. Therefore, sizes must be pre-determined prior to shipment and installation in the field.

\section{Are there special considerations for the framing system?}

For residential and small commercial applications, EC windows and skylights will likely be shipped as a factory-built framed unit, as is typical of most residential windows. Low-voltage wiring details for operable units will be handled differently by each manufacturer. Consult the product specifications to better understand installation issues.

For commercial buildings with curtainwall framing systems, consult with EC window and framing manufacturers to determine how the EC window should be accommodated in the framing and how the low-voltage wiring from the EC window should be routed through the framing system.

As an example, LBNL worked with Wausau Window and Wall systems to specify a site-built curtainwall framing system for our field test facility.

- All windows were non-operable.

- A 3-inch wide framing system was required to meet the minimum edge clearances and accommodate earthquake conditions: expect thermal expansion with these highly absorptive EC windows. A 2-inch or 2.5-inch curtainwall system could be used, according to SAGE, with sufficient edge clearance and room for their connector and wiring.

- A 5/8-inch frame bite is needed to cover the SAGE IGU edge, since the EC coating does not extend all the way to the edge. If the edge is exposed, the uncoated glass will be exposed and direct sunlight could pass through and cause glare.

- The windows were glazed from the exterior. An interior glazed framing system may be preferred to ensure dry conditions for the wiring in the glazing pocket, to facilitate window 
replacement, and ease troubleshooting of the wiring system (no wiring problems occurred over the installed 3-year term despite a few minor earthquakes!).

- To ensure that the wiring was not damaged as the window frame shifts over time (due to settling or earthquakes), a shielded conductor "extension" cable was used instead of lightweight low-voltage wiring. The shielded conductor was threaded through grommeted holes in the framing system (Figure 10). A V-shaped channel was created within the framing system to thread the conductors down to the base of the curtainwall (Figure 11). The pigtail with 2-pin connector extending from the edge of the EC window was connected to one female end of the extension cable in the exterior glazing pocket. The other end of the extension cable exited into the room interior at the base of the curtainwall and was connected to the EC window controller (see the section "What is needed to control EC windows?") located in the wallbox. Typical commercial applications will likely route the wiring up to the ceiling.

Curtainwall details developed for the LBNL field test facility can be found at the end of this guide.
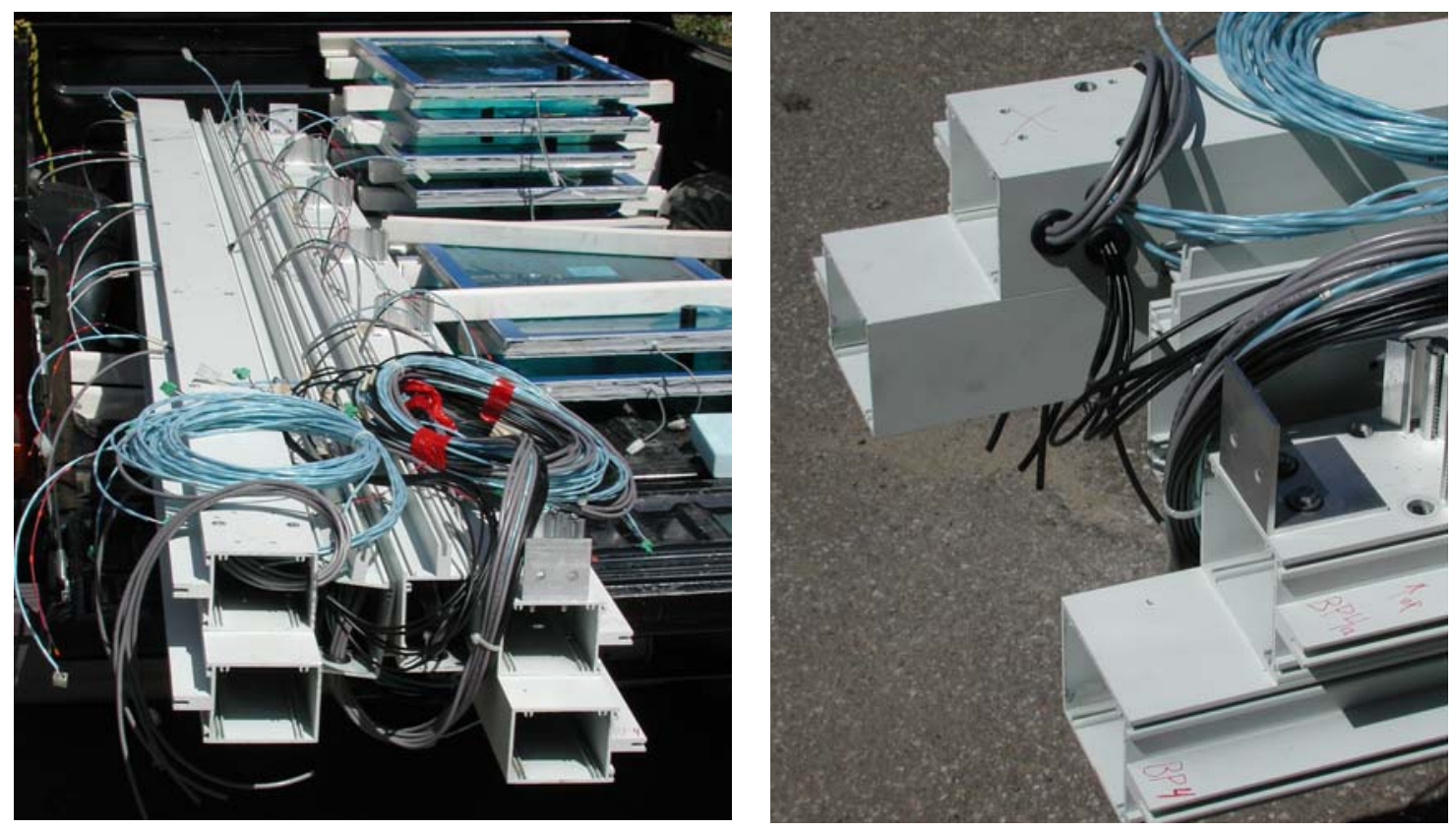

Figure 10. Stacked vertical framing members (left) used in the LBNL Window Testbed Facility showing the low-voltage wiring extending out from the base of the framing member and vertically at equally spaced distances (five IGUS were installed vertically). Detail of the grometted penetrations through the framing members (right). This installation required more cables than needed for a typical installation because LBNL added additional monitoring instruments on the EC IGUs. 

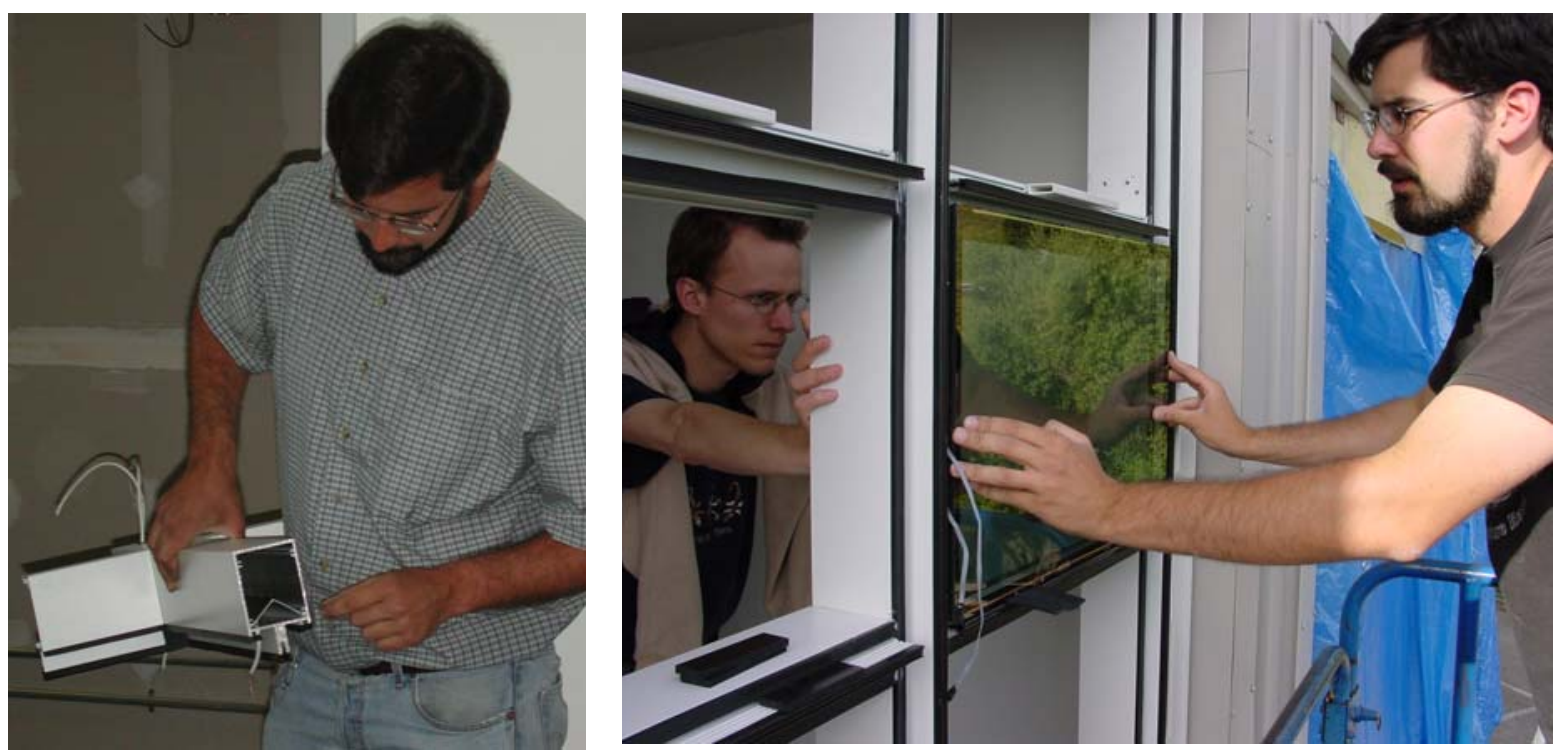

Figure 11. V-channel used to thread cabling through the vertical framing members (left). LBNL installation of EC windows using an exterior-mounted curtainwall system (right).

Factory-built, unitized curtainwall systems could solve some of the trade and labor union issues associated with electrochromic windows. Electricians will likely claim the tasks of pulling wiring through the framing system and connecting the $\mathrm{EC}$ window in the glazing pocket, conflicting with the curtainwall contractor.

\section{What is needed to control electrochromic windows?}

\section{Two-state control (fully bleached or fully colored)}

EC windows will typically be sold with a manually operated switch that allows the occupant to change the tint level of the window between fully bleached and fully colored. For example, SAGE Electrochromics provides a wall mounted on-off switch with LED lights that blink to indicate when switching is occurring. For a previously offered product with intermediate-state control, a pushbutton controller was mounted near the window wall. A user could push an up or down button to set the window to one of five different tint levels. LED lights for each of the tint levels would blink while switching, stop when completed switching, then turn off after several minutes. For networked systems, each EC window or set of windows could be controlled via a PC desktop user interface, as was done in the LBNL field tests.

EC window controllers (i.e., integrated circuit (IC) boards) are required to switch the windows. The EC controller regulates the current and voltage delivered to each window. For on-off control, a single multiplexed EC controller may be used to operate multiple windows. 
The EC controller can be located in the same wallbox as the on-off switch if there are a small number of windows being controlled by the switch (e.g., four windows, Figure 12). The wiring from the EC windows and the low-voltage power supply is fed into the wallbox.

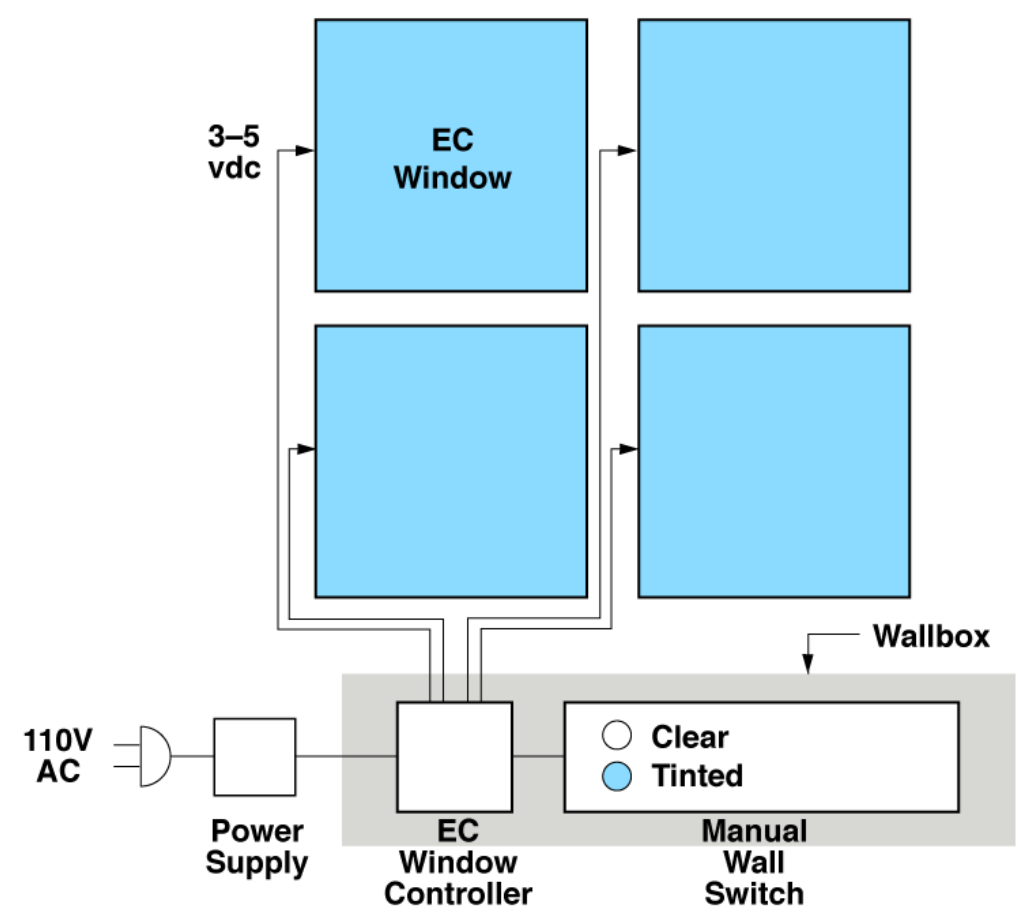

Figure 12. Diagram of a small installation of EC windows with manually-operated wall switch (e.g., single private office).

For larger window walls consisting of many window units, the low-voltage wiring from the EC windows can be terminated in a junction box (using screw terminals, wire nuts, etc.) in the ceiling, then a multi-conductor power cable (gauge defined by distance) can be run to the electrical closet or location where the EC window controllers are housed (Figure 13). The low-voltage power supply (i.e., switching power supply providing bipolar DC voltage) would be located in the electrical closet with the EC controllers. The signal from the on-off wall switch would be run to the electrical closet via a separate serial communications cable (RS232 or RS485). 


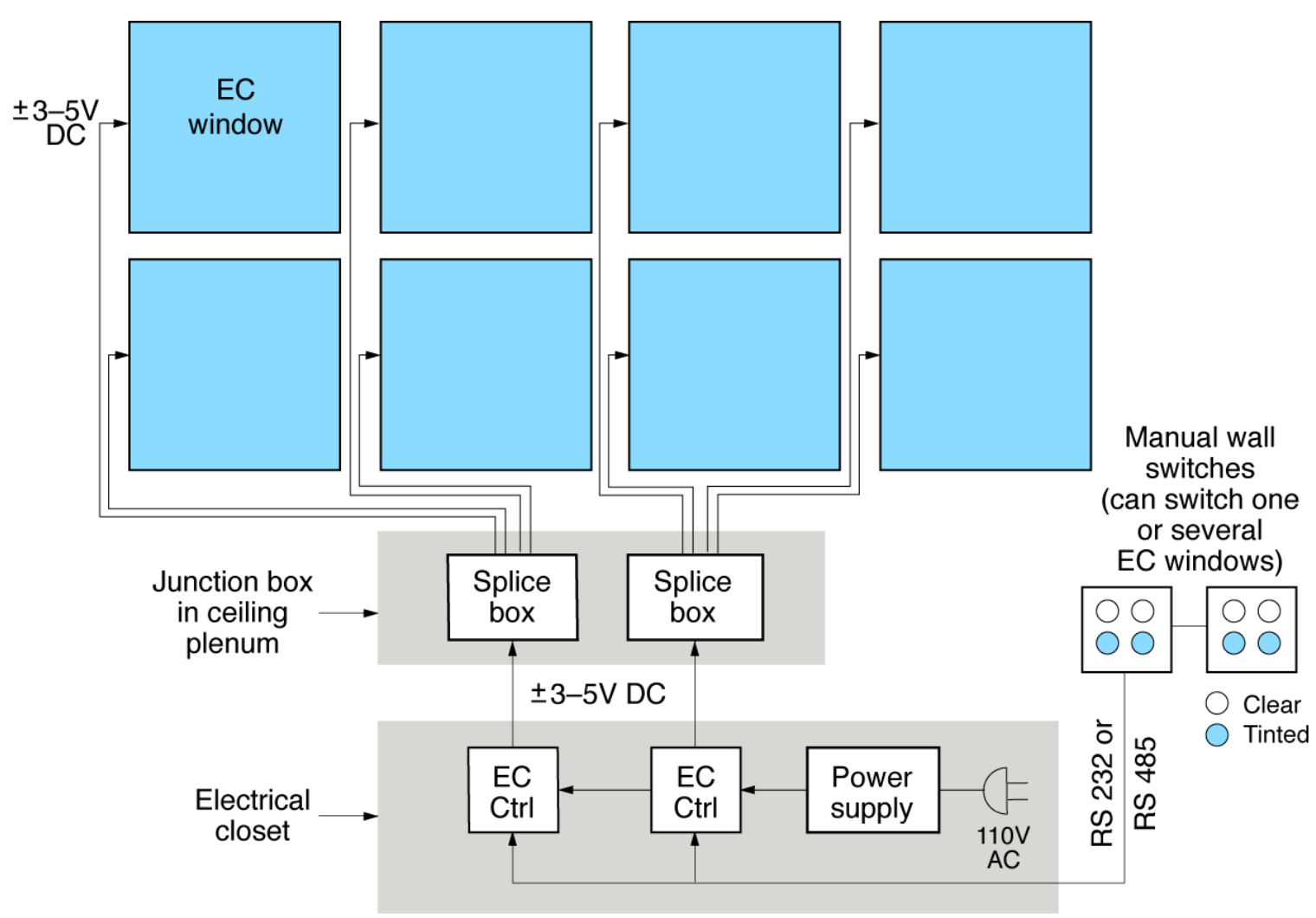

Figure 13. Diagram of a large installation of EC windows with manually-operated wall switches and EC controllers located in an electrical closet.

\section{Intermediate-state control (fully bleached, fully colored, and levels of tint in-between)}

Intermediate-state control requires careful assessment of current and voltage to the window. For the SAGE system, the wiring and control system would be the same as for two-state control. Installation and commissioning the $\mathrm{EC}$ window system must be conducted carefully to ensure that the EC windows are connected to their designated controller.

For future applications, EC windows will have intermediate-state transmittance control and be integrated with other building systems, such as a dimmable electric lighting system. This would enable one to achieve optimal control of the building environment.

\section{Automated control}

Automatic control of the EC windows would require a supervisory control system and possibly sensors, depending on the control objective. At present, SAGE offers the ability to interface with a supervisory control system but no manufacturer offers automated control systems (sensors + 
control smarts). Application software could be developed by the building engineering or controls team. A transmittance value would be computed by the supervisory control system software then sent as a command to the EC window controller, similar to the on-off switch. The supervisory control system could be an independent proprietary EC control system or be interfaced with other proprietary building control systems (lighting, HVAC, etc.) via a gateway link. A manuallyoperated keypad located within the space should be provided to enable override of the automatic system. LBNL devised an integrated EC window and daylighting control system. This system is described in the project's final report.

\section{Single- versus grouped window control}

For a window wall composed of multiple window units, individual EC windows could be controlled separately (Figure 6, 14 and 15). If the window wall is composed of four windows, for example, the wall-mounted on-off switch would have four switches with proper labeling so that the user could ascertain window position. Individual windows could also be grouped into zones so that all the windows in the upper row, for example, could be controlled separately from all the windows in the lower row. If the windows are controlled via a network, window grouping could be reconfigured in software as space changes are made, as opposed to physical re-wiring.

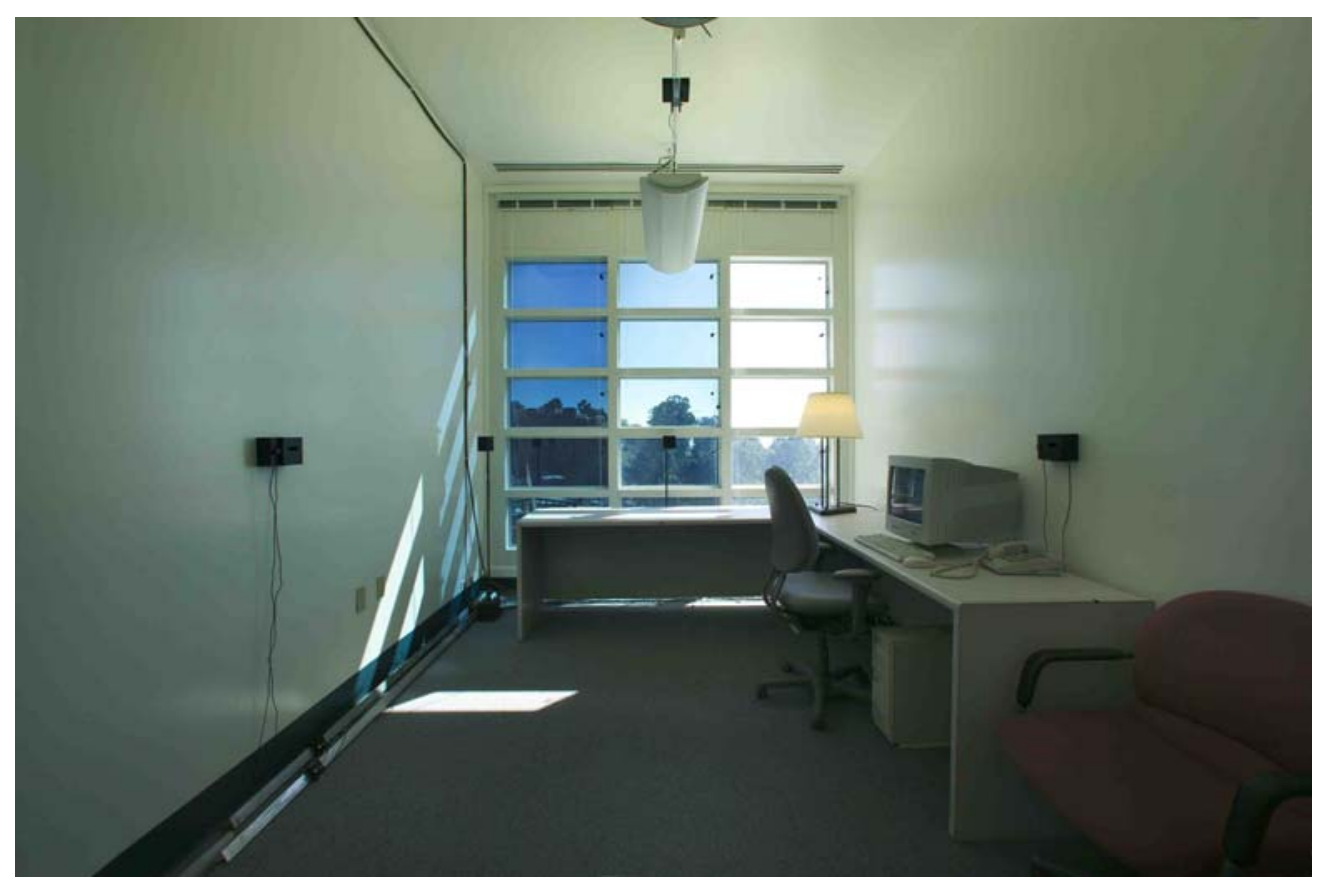

Figure 14. Diagram showing a zoned window wall. 


\section{Do EC windows need to be commissioned after installation?}

Commissioning should be done typically by the window contractor or manufacturer prior to building occupancy. This ensures that the system is operating as intended in the specifications. For manually-operated systems:

- Verify that the windows are operating properly.

- Verify that the on-off switches are labeled so that it is clear which switch controls which window or group of windows.

For automated systems and those with intermediate-state control, more extensive tests will be required to commission the window system.

\section{What are the maintenance requirements of EC windows?}

If the EC windows are operating properly, the windows require the same maintenance as conventional windows.

If the EC windows are not operating properly due to electrical problems, the system should be diagnosed to determine if there are any loose or broken connections, problems with any of the electrical components, or problems with the EC windows themselves.

\section{Are there any CSI specifications developed for EC windows?}

Consult SAGE Electrochromics website. They have some downloadable specifications that detail their product line. There are no other specifications available from other manufacturers at this time.

\section{Will EC windows have NFRC labels?}

All windows sold in California (and many sold in other states) must be labeled with a standardized National Fenestration Rating Council (NFRC) window label. The Dynamic Glazings committee of NFRC has recently adopted technical rating and certification procedures that will enable manufacturers to rate products in 2006 with whole-window TV and SHGC switching ranges 
(values in fully bleached or fully colored states). These values will appear on the label, providing the specifier and consumer with information to compare EC window products.

There are a number of additional issues of interpretation that need to be addressed as the labels come into use. For example, in terms of complying with Title 24 , which of several label values (fully colored, fully bleached, or intermediate values?) should be used to assess compliance with both prescriptive and performance based implementations of Title 24? The operation of the EC window AND its switching range dictate its energy-efficiency in buildings. LBNL is involved with the manufacturers and with NFRC on these issues, so that when products begin to be specified in 2006 they can be addressed by code officials.

\section{How are dynamic windows accommodated in Title-24 and ASHRAE 90.1?}

At present, the code does not provide energy credits for manually-operated interior shades and is unlikely to provide credits for a manually-operated electrochromic window. For automated shades and EC windows, the prescriptive method could be used to obtain energy credits if the automated systems cannot be manually overridden by the occupants. This leads to problems with occupant acceptance and can slow the rate of market adoption. Better compliance methods should be developed for dynamic windows. 


\section{Performance Benefits of Using Electrochromic Windows}

\section{What are the benefits of using EC windows?}

For EC windows with intermediate-state control, which may be commercially available in the next several years, LBNL quantified the energy and non-energy benefits of automated EC windows that are integrated with daylighting control systems (dims lights as daylight increases). With onoff control, the benefits will be similar but likely of lesser magnitude:

- Significantly greater access to outdoor views.

- Reduced need to use blinds and shades.

- Significant lighting energy use savings if the window is zoned and controlled properly.

- Significant cooling load savings, depending on the usage patterns of manually-operated interior shades.

- Significant peak demand reductions.

- Reduction of required HVAC capacity due to reduced peak loads.

- Enables active load management, demand side management and demand response under peak load conditions.

These benefits were quantified for commercial buildings with vertical windows and principally for office buildings where occupants will draw blinds and shades in order to perform computer-based and other work tasks more comfortably.

For residential applications, consult the "Resources" section for more information.

\section{What are the energy benefits of using EC windows?}

To achieve significant energy savings while meeting visual comfort requirements in typical commercial office buildings, the EC window wall should be zoned (Figure 15) and controlled with intermediate-state control to balance daylight and glare. A Venetian blind should be combined with the EC window to block direct sun if a) the occupant's field of view combined with window orientation and design causes frequent views of the sun orb, $b$ ) if the minimum transmittance of the EC window is greater than approximately $\mathrm{TV}=0.03$, and c) if cold weather combined with partly cloudy conditions cause the EC window to switch to this lowest state more slowly than desired by the occupant (see "What do people think of EC windows: About visual comfort"). 


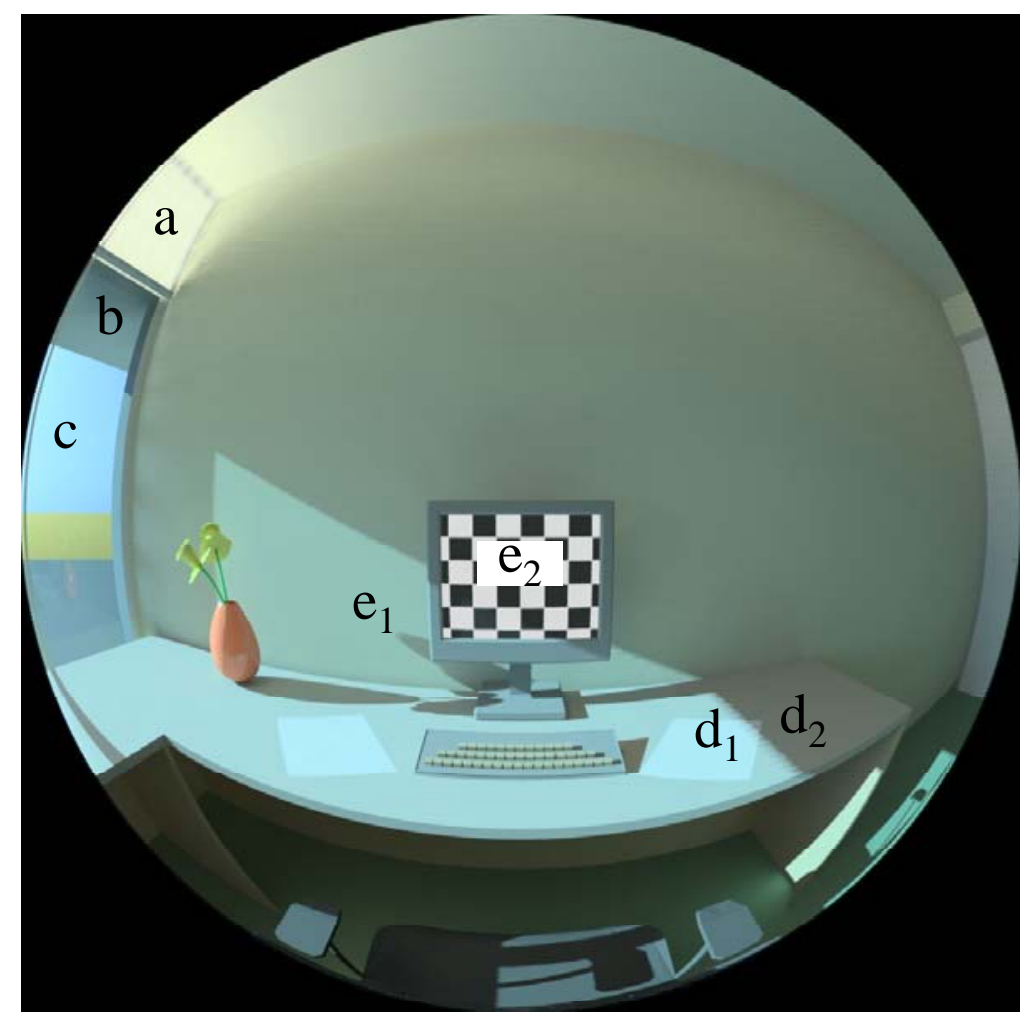

Figure 15. Radiance simulation of a south-facing private office at 11:30 on a clear winter solstice day. This image illustrates the EC control algorithm for visual comfort. Direct sun is blocked from the occupant's field of view by the upper zone's Venetian blind (a) or by an overhang (b). This upper EC zone (b) is controlled to admit daylight. The lower EC zone (c) is switched to $T v=0.05$ to minimize luminance contrasts between the VDT (e2) and sunlit (e1, d1) surfaces and between paper-based tasks that are sunlit (d1) and shadowed (d2). The luminance of the lower window is controlled (c). View out is preserved (c).

With the zoned EC window configuration described above (but no overhang), a full-scale monitored field test of a zoned EC window with a visible transmittance (TV) range of TV=0.60-0.05 yielded the following results:

- Average daily lighting energy use savings in a private south-facing office in Berkeley, California were $10-23 \%$ given non-optimized glare/daylight control, compared to a conventional high-transmittance window $(\mathrm{TV}=0.60)$ with a fully-lowered, slightly open Venetian blind (comparable level of glare control to EC window) with the same daylighting control system.

- Savings of $44 \%$ are attained if the reference case has no daylighting controls, as is the norm in building practice today.

- Cooling savings were small with this comparison, but could be increased if the EC windows are controlled based on occupancy (e.g., Tv=minimum if unoccupied for a certain period - but switching speeds would need to be taken into account). 
These savings were in addition to that which would have been achieved by the daylighting control system alone, since both the reference and $\mathrm{EC}$ window case had the same daylighting control system. An example of EC window transmittance control on a mostly sunny day is given in Figure 16.

With simulations, annual lighting energy use savings of the same zoned system were estimated to be $48-67 \%$ with optimized control. To achieve this level of savings would require more sophisticated controls that at present are not commercially available.

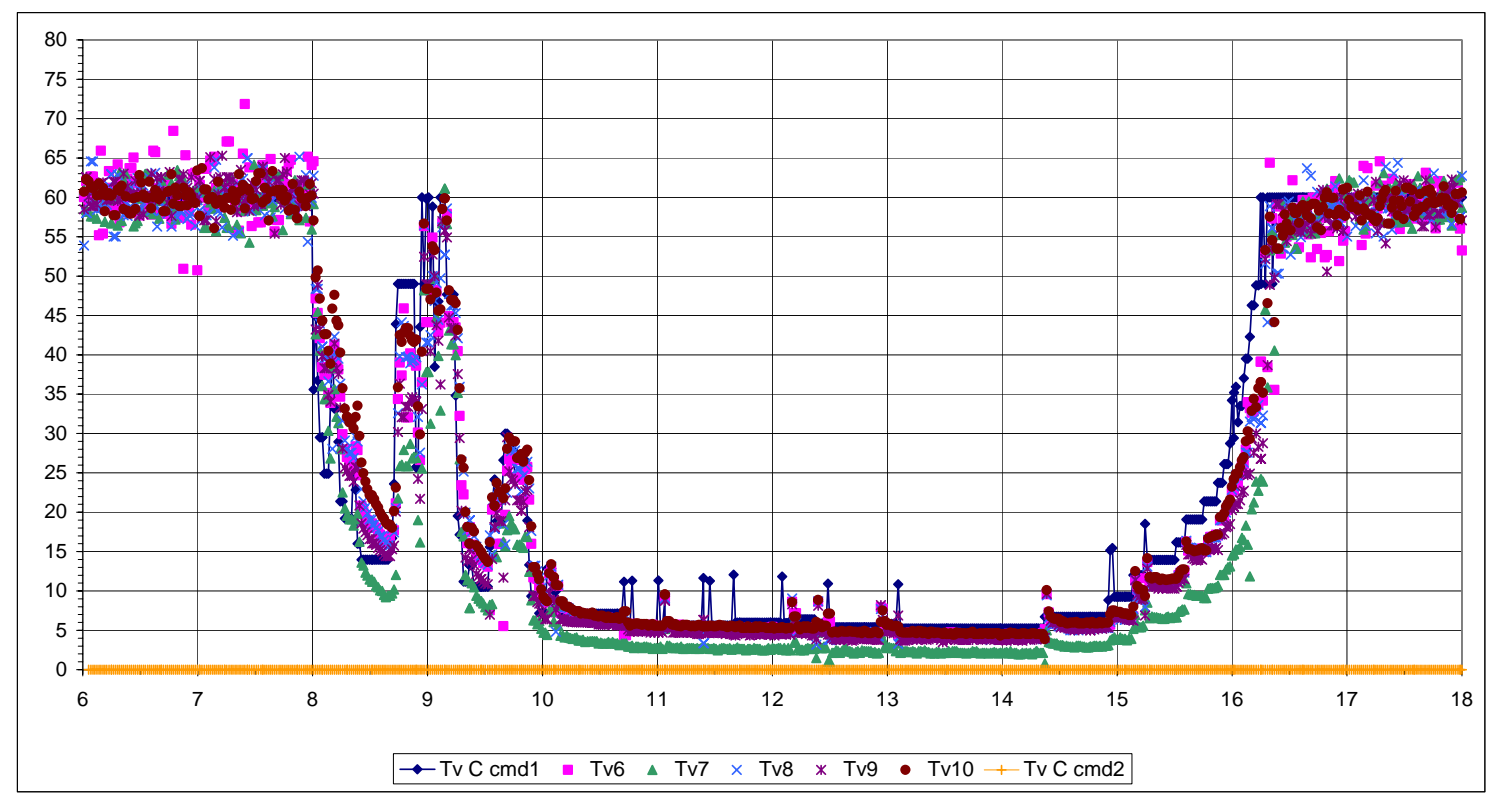

Figure 16. Example of the daylight-controlled EC window and daylighting control system on December 11, 2004. Unshaded EC windows are tinted in proportion to available daylight. The transmittance levels of five of the 15 EC windows are shown in the graph as Tv6 through TV10.

Energy savings are greatest in warm to hot climates (i.e., southern sunbelt region of the U.S.) where large-area windows are specified for the south, east, and west-facing orientations. See the "Resources" section for the project's final report and technical reports for more information on the magnitude of these savings for various climates (e.g., for Title-24's 16 California climate zones), window sizes, window orientations, and base case conditions.

\section{What peak demand reductions can be expected from EC windows?}

Reducing the peak demand in buildings is important because there is a limited supply of generation capacity to meet peak requirements. Peak electricity demands occur typically during hot sunny summer periods and have more recently been the cause of staged blackouts in certain 
regions of California. There is significant pressure in states like California and New York to avoid building new power generation facilities to meet growing peak requirements. Developing active load management and demand responsive technologies and control strategies can help in this regard. Consumers can also derive significant utility cost reductions if such load shed capabilities are available in their building.

Solar heat gains and lighting energy use constitute a significant percentage of a commercial building's perimeter zone peak load. Peak cooling load reductions and therefore peak demand reductions can be significant because the $\mathrm{EC}$ window can substantially reduce solar heat gains when switched to its maximum colored state.

Referring to the LBNL field test data and given that measurements were made for a south-facing window orientation, the peak condition occurs on a clear winter day when solar irradiance levels are the highest of the year. Peak cooling load reductions due to solar heat gains were a maximum of $26 \%$ and $19 \%$ compared to an unshaded and fully shaded reference case if the EC window is controlled to its most colored state (solar heat gain coefficient $(S H G C)=0.09$; Figure 17).

Reference with no blind

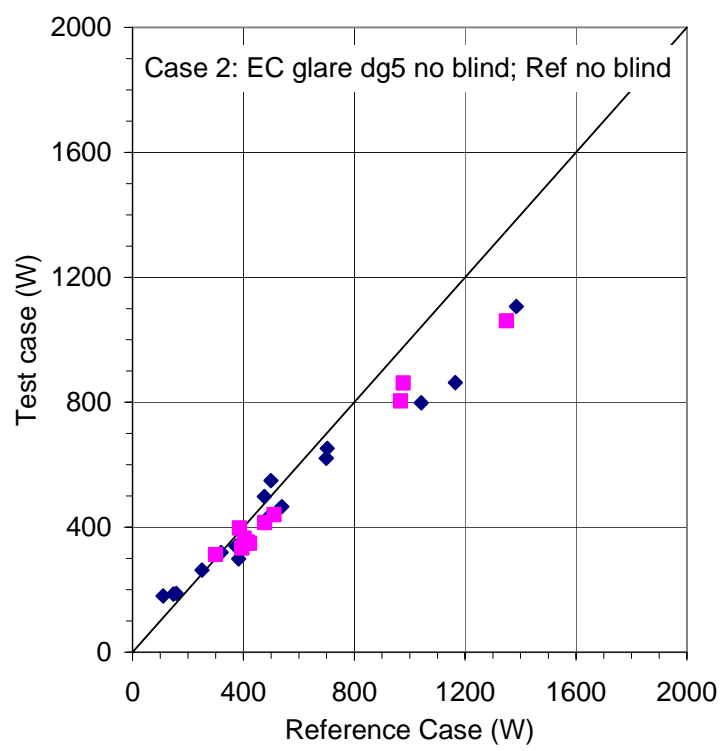

Reference with blind

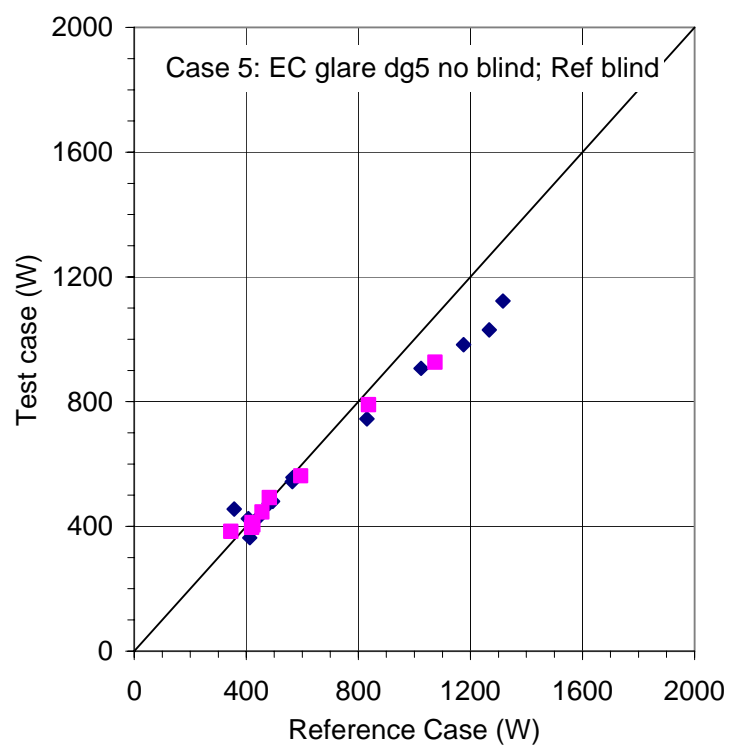

Figure 17. Field measured hourly peak cooling load due to heat gains from window and lights for the single-zone EC system controlled by glare (TV=0.05) compared to the reference case with (right) or without (left) fully-lowered Venetian blinds (45 slat angle). Peak loads occurred above the 800-1000 W level for both the reference and test (EC window) cases. [Lee et al. 2006]

Lighting peak demand reductions depend on the assumptions for the reference case. If the reference case's window is large, has high-transmittance glazing, and has the same daylighting controls as the EC case, then peak lighting load reductions are likely to be very small or zero. If 
the base case has no lighting controls, peak demand reductions could be $70-100 \%$, depending on the minimum or standby requirements of the test case's dimming electronic ballast.

Peak demand reductions are greatest in warm to hot climates (i.e., southern sunbelt region of the U.S.) where large-area windows are specified for the south, east, and west-facing orientations. See the "Resources" section for the project's final report and technical reports for more information on the magnitude of these savings for various climates (e.g., for Title-24's 16 California climate zones), window sizes, window orientations, and base case conditions.

\section{What HVAC capacity reductions can be expected from EC windows?}

Conventional commercial building heating, ventilation, and air-conditioning systems are sized based on the peak cooling load in the building. The capacity of the chiller system, for example, can be reduced if EC windows are automated, lowering the capital cost of the building.

For more advanced low-energy cooling strategies or for buildings located in the northern region of the U.S., installation of an air-conditioning (AC) system may be avoided altogether if EC windows sufficiently control window solar heat gains. For example, in Germany, energy codes discourage the specification of AC systems in new buildings. The SWIFT study investigated EC window control strategies to determine if the interior space temperature could be passively maintained within acceptable limits. EC windows were colored during the summer and bleached during the winter for passive cooling and heating of the commercial building. Glare and direct sun control was achieved not by the EC window but by an interior Venetian blind. Technical reports and summary information about the SWIFT three-year EU study are available at http://www.euswift.del.

\section{How does EC windows increase visual comfort?}

The assessment of visual comfort remains challenging as the various comfort indices in use today have known limitations. LBNL explored new metrics and developed new approaches that may provide better techniques for assessing these important building and occupant impacts. EC windows can meet most visual comfort requirements if the occupant's field of view excludes views of the orb of the sun.

With intermediate-state control, an analysis of monitored data was made to assess visual comfort. EC windows provide a benefits package of energy savings and comfort that exceeds conventional "window plus blind" systems. In comparison to the reference case of windows with 
the blinds down, EC windows offer the possibility of higher use of daylight and lower energy consumption than normal windows, which will often have the blinds lowered, while at the same time providing better visual comfort than normal windows with the blinds raised. The EC system has the added advantage over a window blind system of being able to provide views out for a larger percentage of the day.

Occupant's opinions were surveyed in the LBNL field test facility. See the "What people think" section below.

High dynamic range luminance images taken in the LBNL field test facility provided more detailed information on the visual comfort levels resulting from the use of EC windows (Figure 18). This study focused on the question of whether visual comfort requirements could be met given a largearea window with the EC fully colored $(\mathrm{TV}=0.05)$ :

- Under clear sky equinox or solstice conditions, the EC window at TV=0.05 maintained the luminance ratio between the paper and VDT task below the 3:1 recommended limit except when direct sun was on the paper task (maximum ratio of 6:1).

- If one's eye is poorly adapted to the brightness of the window wall (for example if one was seated at the back of the room facing the window), then the computed daylight glare index rises to almost "just uncomfortable" levels during midday winter solstice hours.

- If one looks directly at the sun through the darkened window, the luminance of the orb of the sun was greater than $60,000 \mathrm{~cd} / \mathrm{m}^{2}$ on the winter solstice, which is still unacceptable, but direct view of the sun is never assumed to be desirable. 


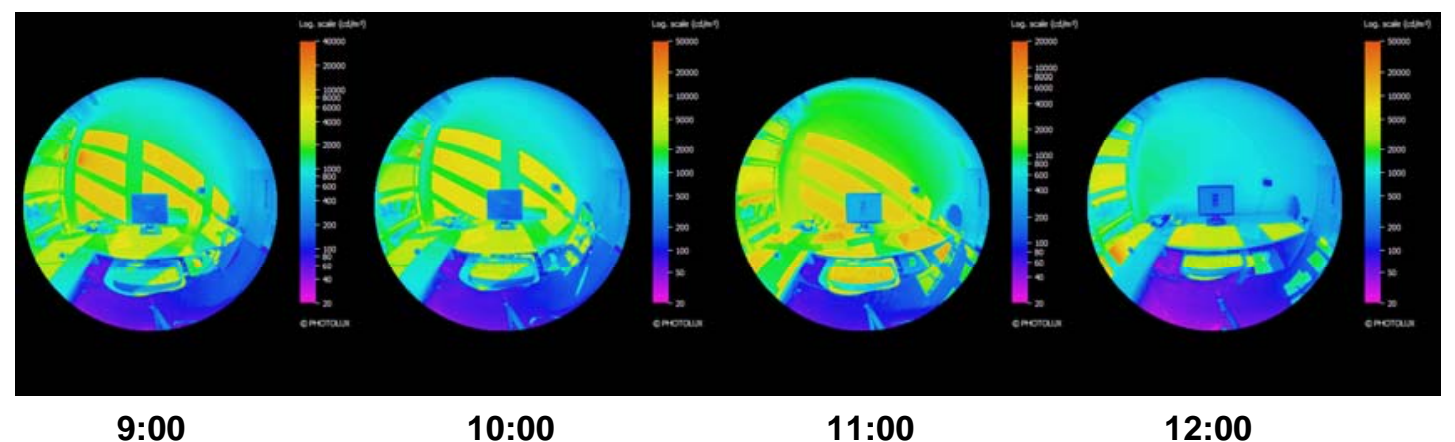

9:00

10:00

11:00

$12: 00$

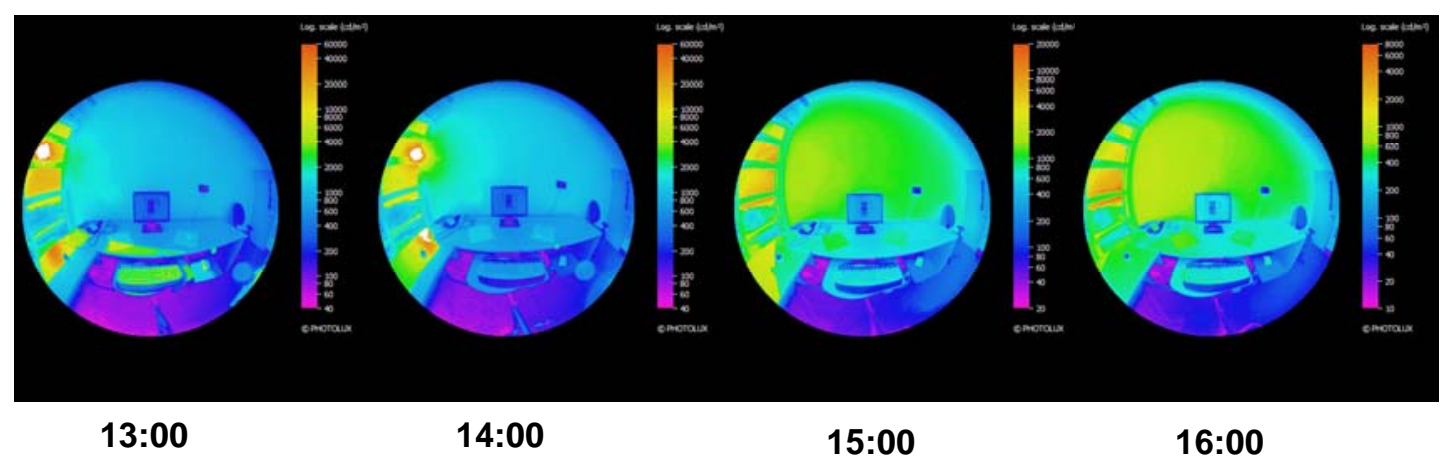

Figure 18. Time lapse luminance images of the testbed on a clear sunny winter solstice day with a southfacing EC window at TV=0.05. View of LCD VDT from the seated position of the occupant. Note that the maximum value on the falsecolor luminance scale differs for each image. The sun orb is visible at 13:00 and 14:00.

\section{How is view increased when EC windows are used?}

Occupants will modify their window when they are uncomfortable. Field studies suggest that if interior shades are lowered, they are rarely raised when uncomfortable conditions are no longer present. Occupants will lower shades or blinds because:

- There is direct sun in their field of view or the sunlight causes thermal discomfort.

- The brightness of the window causes glare.

- There are reflections in their computer monitor.

- They desire privacy (particularly on the lower floors of buildings or in urban environments).

A Radiance-Mathematica simulation study was used to determine likely blind use patterns if the occupant controlled the blind to achieve visual comfort. The percentage of year that the occupant has a view out is significantly greater (Figure 19): $98 \%$ for the EC case versus $38 \%$ for the reference case ( $\mathrm{TV}=0.60$ with an interior Venetian blind). We speculate that $\mathrm{EC}$ windows can lead to increased greater occupant satisfaction and perhaps increased productivity and a more healthful environment based on these simulation data. 
a)

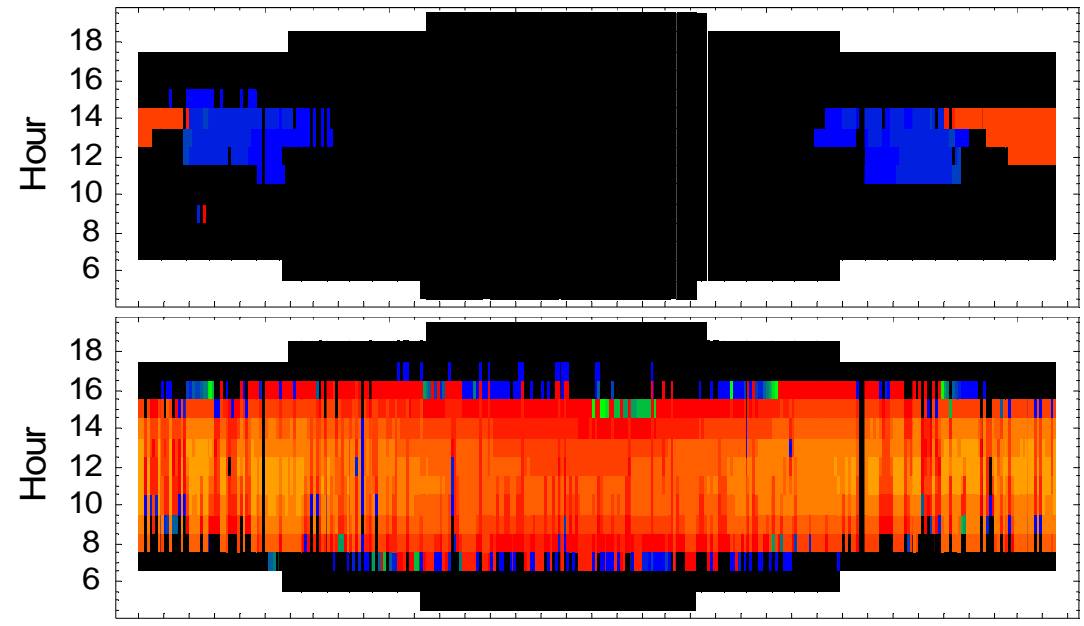

Blind covers upper pane:

Blind covers whole window:

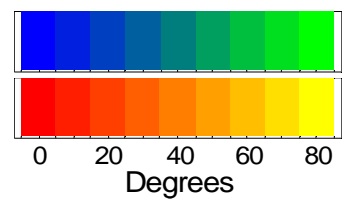

Figure 19. Blind use patterns throughout the year for: a) electrochromic windows without overhang, and b) reference window without overhang. The $x$-axis is the day of the year with the left edge is day 0 and right edge is day 365. Black means that there is no blind required. White means that the sun was not up. Blind tint angle is given for each hour (0 degrees is a horizontal slat angle).

Occupant's opinions and patterns of blind use were surveyed in the LBNL field test facility. See the "What people think" section below.

\section{How does one compute the energy savings benefit of EC windows?}

To evaluate the energy and peak demand performance impacts of EC windows on a specific building design, engineers can use DOE-2 or Energy-Plus (http://gundog.lbl.gov/index.html). These programs have the ability to model control algorithms for EC windows based on hourly weather or room conditions such as daylight illuminance, exterior vertical irradiance, transmitted solar irradiance, etc. although for intermediate-state control, not on-off control of the EC window. A DOE-2 user-defined function can be developed to model on-off control.

To properly evaluate the thermal and daylighting effects of EC windows, the EC window must be created using spectral data with the Optics and WINDOW5 software. Spectral data for the SAGE electrochromic window are now included in the International Glazing Database (IGDB \#1200 and \#1201 for clear and tinted states, respectively). Software and spectral data are available for free and can be downloaded at: http://windows.Ibl.gov/software/default.htm. The user creates two WINDOW5 files, one each for the fully tinted and fully bleached states, then references these data files in the building energy simulation input file. 
To properly estimate energy impacts, EC windows must be controlled for visual comfort as well as for energy-efficiency. For an accurate and in-depth evaluation of the visual environment, the Radiance visualization program can be used to compute daylight illuminance and luminance of various interior surfaces including the windows. A technical report using Radiance provides some examples on how this program can be used to develop window control strategies.

\section{What is the payback of EC windows?}

Given its emerging technology status, the cost of EC windows remains around $\$ 100 / \mathrm{ft}^{2}$-glazing. The cost is likely to decrease as volume of sales increases. Compared to conventional spectrally selective low-e windows (low-e coated windows with a high daylight transmittance and low solar heat gain coefficient) at $\$ 10-15 / \mathrm{ft}^{2}$-glazing, the cost of EC windows cannot be justified at this time by energy savings alone. Other potential capital and operating cost savings should be considered for a proper apples-to-apples comparison; e.g., possible reduction in HVAC capacity and maintenance requirements, reduced need for blinds or shading systems with associated maintenance and replacement costs, and reduced need for permanent solar control devices (overhang, fins, frits, etc).

If occupant comfort is translated into productivity dollars, automated EC windows may be cost justified at this price if properly designed and controlled. EC windows enable greater access to outdoor view and can increase interior daylight levels without increasing glare, leading to increased occupant comfort, performance, and perhaps productivity. 


\section{What do people think of electrochromic windows?}

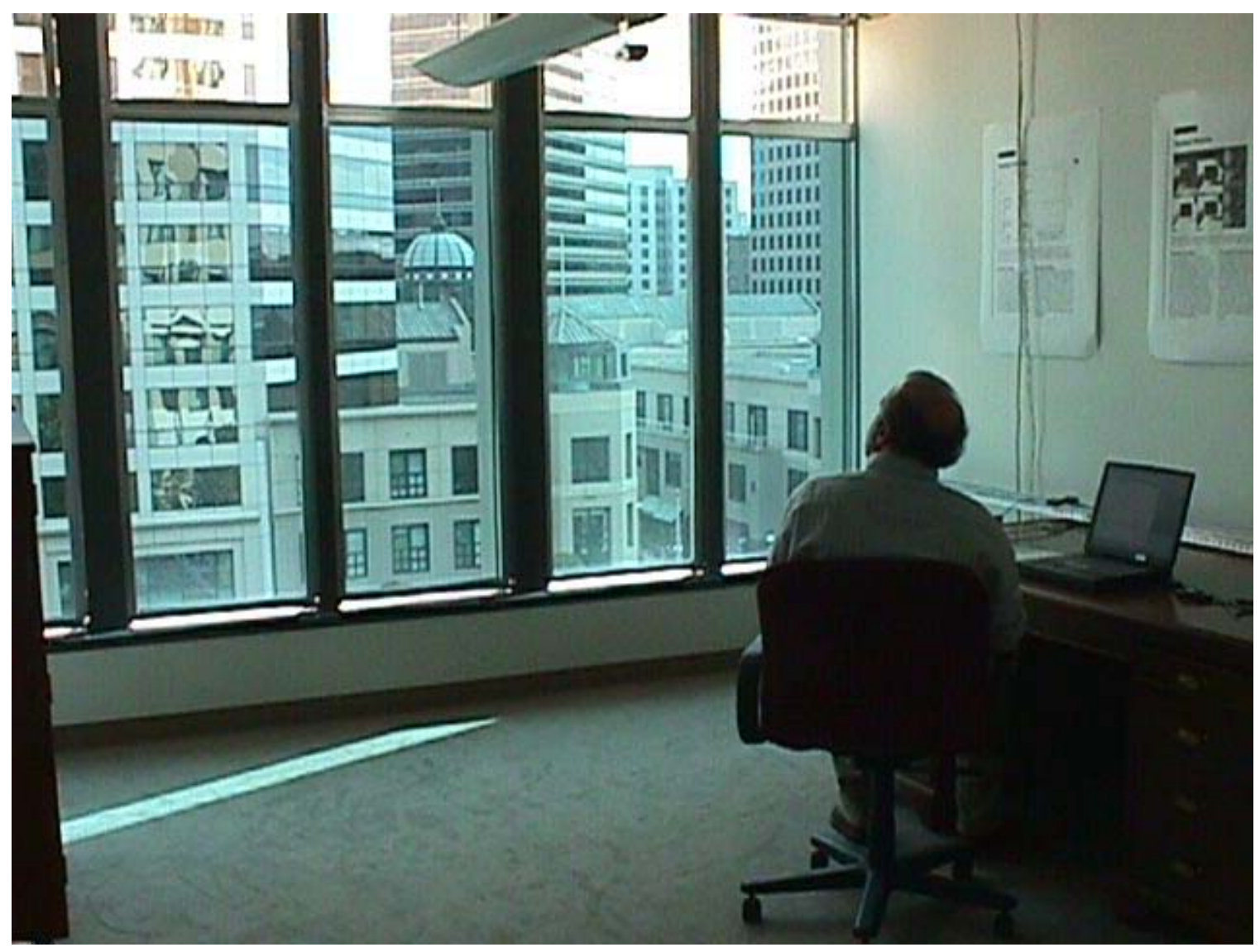

Figure 20. An LBNL field test of large-area electrochromic windows conducted in 1997.

Several field studies have been conducted to understand user acceptance and satisfaction with EC windows [Wienold 2003, Zinzi 2006]. LBNL conducted a 2005 study [Clear et al. 2006] where 43 people (or "subjects") were each asked to work in a south-facing private office for half a day. The study was conducted in the winter, presenting a severe test of the ability of the EC window and Venetian blind to control glare.

During the test, the $\mathrm{EC}$ windows had a continuous transmittance range of $\mathrm{TV}=0.60-0.03$ and the overhead fluorescent lighting was dimmable. The subjects worked for approximately one hour with the windows in three different "modes": 1) reference static window (Tv=0.60), 2) automated EC window, and 3) semi-automatic EC window where the user had controls to set their desired total interior illuminance level and EC window tint level when there was direct sun (default was maximum tint level). 


\section{About the EC Window Itself}

In general, the subjects were satisfied with the various attributes of the EC window (appearance, time to lighten/darken, and color) but some subjects had specific complaints:

- The windows had a faint yellow tint when fully bleached and a deep blue tint when fully darkened, but only two subjects had significant negative reactions to the color.

- One subject was not satisfied with the overall appearance of the window wall, reacting negatively to the color differences between window panes.

- Two subjects thought that the individual EC window panes (35 inches wide by 18 inches tall) were too small ( 2.5 rating, where $2=$ not satisfied and $3=$ just satisfied).

- One subject was very dissatisfied with the lack of control of individual EC window panes.

- Three subjects were not satisfied because the transmittance range was insufficient to control glare from direct sun.

- Subjects were asked specifically whether they would be more satisfied with the electrochromic windows if they could darken more than they did. The majority (58\%) of the subjects responded affirmatively. Subjects who wore glasses were more likely to answer affirmatively (73\% versus $19 \%)$.

- Seemingly contrary to this, occupants on average set the "glare" transmittance level (for conditions when there was direct sun) to a higher transmittance than the fully colored transmittance level (Tv=0.03). Fifty percent of the subjects left the setting at $T v=0.03$. The average setting selected by users was $T v=0.11$ in the presence of direct sun.

- On average, subject response to the switching speed of the windows was approximately midway (average $=3.6$ ) between just satisfied $(=3)$ and satisfied $(=4)$, but five subjects (12\%) were not satisfied.

\section{About Automated Control}

Regarding automatic control of EC windows compared to conventional static windows (both had manually-operated Venetian blinds):

- An automatically controlled EC window consistently provided higher satisfaction than a static window $(\mathrm{Tv}=0.60)$ and also resulted in significantly less blind use.

- Preferences were strongly related to perceived reductions in glare as well as measurable reductions in window luminance. Occupants were more satisfied with the following attributes of the EC window control system than the reference mode: glare control, control 
of reflections on the computer monitor, and ability to control the windows and lighting system.

- The interior Venetian blinds were used by $23 \%$ of the occupants with the automaticallycontrolled EC window. With the static window, the blinds were used by $62 \%$ of the occupants.

\section{About Visual Comfort}

With respect to visual comfort and lighting quality, the EC alone was insufficient to control window glare, but the blinds were used less frequently (fully raised) with the dynamic EC modes than the reference mode:

- Subjects rated their overall level of glare sensation as barely above perceptible (2.3 on average, where $1=$ =not perceptible, $2=$ perceptible, $3=$ =acceptable, $4=$ uncomfortable, and $5=$ intolerable) for the automated EC window. For the reference static window, the glare sensation was 2.7 on average. This difference was not statistically significant, indicating that the subject (after having lowered the blind) was able to control glare adequately with any of the three modes. The reference mode tended to have more light available from the window than the automated EC window, even when the blinds were lowered.

- The Venetian blinds were used primarily to reduce glare from daylight or sunlight (57\% of responses) or to reduce the overall brightness of the room (33\% of responses). The blinds were used more often with the reference static window than with the automated EC window. There was no significant difference in the way they were used, between the different modes, once they were deployed. The tilt angle averaged $70 \pm 15^{\circ}$ (view toward the ground from interior). The average blind height for all modes was about half-way lowered over the window (i.e. $5.5 \pm 3.3(0=$ down, $10=$ up)). This is an average height above the floor of $1.6 \mathrm{~m}$, which allows a seated person a horizontal view out.

- The test room lighting level for the automatic mode was judged just right, 3.08 average (where $3=$ just right and $5=$ too bright) while the reference mode was judged 3.46 on average.

- On a scale of 1 to 5 with $1=$ unnatural and $5=$ natural, the room color rendering was judged 3.4 on average between all three modes. Only one of the 43 subjects felt that the room color rendering was unnatural. The ceiling and walls were painted white. The carpet was gray and the furniture was a warm gray with a slight purple hue. 


\section{About Thermal Comfort}

With respect to thermal comfort, subjects did not complain about thermal discomfort due to the warm surface temperature of the window or direct solar irradiance, perhaps because it was winter:

- The mean temperature rating was "just right" with the EC and reference modes of operation. Despite the fact that subjects were told that the temperature could be changed, two subjects reported being too cold in one of the sessions. For $4 \%$ of the responses, subjects lowered the blinds to reduce the heat from the sun (in all sessions). None of the subjects reported deploying the blinds to reduce a cold draft from the windows.

- There was no clear relationship between the exterior window surface temperature and the subjective temperature ratings. Because of the low-emittance coating $(e=0.15)$, the interior surface temperature of the window did not elevate to levels that would cause thermal discomfort. The average exterior surface temperatures for the automatic and semi-automatic modes were higher than for the manual mode (because the manual mode had the EC in its least absorptive, bleached state), but the difference was not statistically significant. The average exterior surface temperature of the EC window was $30 \pm 15^{\circ} \mathrm{C}\left(86 \pm 59^{\circ} \mathrm{F}\right)$. The lowest temperature was $10-12^{\circ} \mathrm{C}\left(50-54^{\circ} \mathrm{F}\right)$. The highest temperature was $72.6^{\circ} \mathrm{C}\left(163^{\circ} \mathrm{F}\right)$.

\section{About View}

With respect to view:

- A paired comparison test was run between subject's rating of overall satisfaction with the EC window control system, considering or not considering the view (there was a spectacular west view of the San Francisco Bay from the test rooms and the furniture was oriented to enable subjects to look west comfortably). The test confirmed our suspicion that view was important in their overall satisfaction with the EC system $(P<0.01 \%)$, despite a fairly small difference $(0.3)$ in the mean ratios for the two questions.

- A high fraction of subjects faced the window despite the fact that the window was the most commonly cited glare source and that for $90 \%$ of the responses, blinds were lowered to reduce glare or brightness. Approximately $50 \%$ of the subjects using a laptop computer faced the window and almost two-thirds of the subjects faced the window when not using a computer. Facing the sidewall is less glaring but the sun may fall directly on the computer monitor if the blinds are not lowered. Facing the window enables a direct 
view out and prevents the sun from falling on the monitor while keeping reflections off the monitor but creates contrast problems between VDT screen brightness and view brightness.

- Foot traffic near the windows was minimal and none of the subjects reported deploying the blinds for privacy. Blinds were deployed $4 \%$ to decrease the level of visual stimuli from the outside. 


\section{Resources}

\section{Industry Contacts}

At present, SAGE Electrochromics, Inc. is the only manufacturer selling electrochromic insulating glasss units:

Mike Myser

SAGE Electrochromics, Inc.

One Sage Way

Faribault, MN 55021

(507) 331-4903

http://www.sage-ec.com

SAGE sells IGUs to Velux for their switchable electrochromic skylight product line: electric venting skylights, fixed skylights, and fixed curb-mounted skylights in various rectangular sizes.

http://www.veluxusa.com/

Other U.S. companies are also developing electrochromic window products but have not yet come out with a commercial product:

Dr. Thomas Guarr

Gentex Corporation

600 N. Centennial Street

Zeeland, MI 49464

(616) $772-1590$ ext. 434

Mr. Jay Wolfington

Eclipse Energy Systems, Inc.

2345 Anvis Street North

St. Petersburg, FL 33710

(727) 344-7300 x206 


\section{California Utility Contacts}

California Utilities have emerging technology programs that assist building owners and architectural/ engineering ( $\mathrm{A} / \mathrm{E}$ ) teams to overcome the technical and cost hurdles of adopting a new technology. The following contacts may be able to assist consumers located in their service territory and point consumers to locations where the EC window can be viewed firsthand.

Bill Burke

Pacific Energy Center

851 Howard St.

San Francisco, CA 94103

(415) 973-9951

wxb0@pge.com (that's a zero after the 'b')

Connie Buchan

Sacramento Municipal Utility District

6301 S Street

P.O. Box 15830, MS-A226

Sacramento, CA 95852-1830

(916) 732-6404

cbucha1@smud.org

Doug Avery

Southern California Edison

6042 N. Irwindale Avenue

Suite B

Irwindale, CA 91702

(626) 633-7182

davery@sce.com

A.Y. Ahmed

San Diego Gas \& Electric

Southern California Gas

555 W. Fifth St, GT15E3

Los Angeles, CA 90013-1035

(213) 244-5308

aahmed1@SempraUtilities.com 


\section{R\&D Organizations}

\section{Lawrence Berkeley National Laboratory}

Environmental Energy Technologies Division

Building Technologies Program

1 Cyclotron Road, MS-90-3111

Berkeley, CA 94720

Stephen Selkowitz, Building Technologies Program Head, seselkowitz@lbl.gov

Eleanor Lee, Building Performance, eslee@lbl.gov

Tom Richardson, Reflective Hydrides, TJRichardson@lbl.gov

http://windows.lbl.gov/

\section{National Renewable Energy Laboratory}

1617 Cole Boulevard

Golden, CO 80401

Roland Pitts, Durability Testing, Electrochromic Materials, Degradation Mechanisms

Roland Pitts@nrel.gov

http://www.nrel.gov/buildings/windows/durability.html

\section{National Fenestration Rating Council}

Labeling Subcommittee: Dynamic Glazing Task Group

http://www.nfrc.org/

\section{Switchable Facade Technology Project (completed 2003)}

(Headed by Fraunhofer Institute for Solar Energy Systems, Freiburg)

Project documentation and technical reports can be found at:

http://www.eu-swift.de/

An architectural guideline is also available at this site.

\section{Technical Reports}

The "Advancement of Electrochromic Windows" project, supported by the California Energy Commission through its Public Interest Energy Research (PIER) Program and by the U.S. Department of Energy, has produced the following technical reports: 


\section{Final Report}

Lee, E.S., S.E. Selkowitz, R.D. Clear, D.L. DiBartolomeo, J.H. Klems, L.L. Fernandes, G.J. Ward, V. Inkarojrit, M. Yazdanian. 2006. Advancement of Electrochromic Windows. California Energy Commission, PIER. 500-01-023. LBNL-59821.

and the following appendices:

\section{Systems Engineering}

1. Lee, E.S., S.E. Selkowitz, M.S. Levi, S.L. Blanc, E. McConahey, M. McClintock, P. Hakkarainen, N.L. Sbar, M.P. Myser. 2002. "Active Load Management with Advanced Window Wall Systems: Research and Industry Perspectives". Proceedings from the ACEEE 2002 Summer Study on Energy Efficiency in Buildings: Teaming for Efficiency, August 18-23, 2002, Asilomar, Pacific Grove, CA. Washington, D.C.: American Council for an Energy-Efficient Economy. LBNL-50855, Lawrence Berkeley National Laboratory, Berkeley, CA.

2. Lee, E.S., D.L. DiBartolomeo, F.M. Rubinstein, S.E. Selkowitz. 2004. Low-Cost Networking for Dynamic Window Systems. Energy and Buildings 36(6):503-513. LBNL52198, Lawrence Berkeley National Laboratory, Berkeley, CA.

3. Tavil, A. and E.S. Lee. 2005. The impact of overhang design on the performance of the electrochromic windows. Proceedings of the International Solar Energy Society (ISES) Solar World Congress, Orlando, Florida on August 8-12, 2005. LBNL-57020.

4. Lee, E.S. and A. Tavil. 2005. An assessment of the visual comfort and energy performance of electrochromic windows with overhangs. Submitted to Building and Environment, October 14, 2005. LBNL-59064, Lawrence Berkeley National Laboratory, Berkeley, CA.

5. Fernandes, L., G. Ward, E.S. Lee. 2005. Radiance-Mathematica optimization of electrochromic operations for occupant comfort and non-energy provisions. Technical report. 


\section{Performance Impacts}

\section{Energy Use and Peak Demand Impacts}

6. Lee, E.S., D. L. DiBartolomeo. 2002. Application issues for large-area electrochromic windows in commercial buildings. Solar Energy Materials \& Solar Cells 71 (2002) 465491. LBNL-45841, Lawrence Berkeley National Laboratory, Berkeley, CA.

7. Lee, E.S., D.L. DiBartolomeo, S.E. Selkowitz. 2005. Daylighting control performance of a thin-film ceramic electrochromic window: Field study results. Energy and Buildings 38 (2006) 30-44. LBNL-54924, Lawrence Berkeley National Laboratory, Berkeley, CA.

8. Lee, E.S., D.L. DiBartolomeo, J. Klems, Ph.D., M. Yazdanian, S.E. Selkowitz. 2005. Monitored Energy Performance of Electrochromic Windows Controlled for Daylight and Visual Comfort. To be presented at the ASHRAE 2006 Annual Meeting, Quebec City, Canada, June 24-28, 2006 and published in ASHRAE Transactions. LBNL-58912.

9. Lee, E.S., M. Yazdanian, S.E. Selkowitz. 2004. The Energy-Savings Potential of Electrochromic Windows in the US Commercial Buildings Sector. LBNL-54966, Lawrence Berkeley National Laboratory, Berkeley, CA.

10. Klems, J. 2004. Thermal calibration of the windows testbed facility. Technical report.

\section{Occupant Impacts}

11. Clear, R.D., V. Inkarojrit, E.S. Lee. 2005. Subject responses to electrochromic windows. Submitted to Energy and Buildings, February 23, 2005. LBNL-57125, Lawrence Berkeley National Laboratory, Berkeley, CA.

12. Inkarojrit, V. 2004. Analysis of visual comfort using high-dynamic-range luminance images. Poster report. http://windows.Ibl.gov/comm_perf/electroSys-cec.htm.

13. Clear, R.D. 2005. Assessment of visual comfort study in a full-scale electrochromic window testbed. Technical report. http://windows.lbl.gov/comm_perf/electroSys-cec.htm.

\section{Information Resources}

14. Exerpt from: Carmody, J., S. Selkowitz, E.S. Lee, D. Arasteh, T. Wilmert. 2004. Window Systems for High Performance Commercial Buildings. New York: W.W. Norton and Company, Inc.

15. Lee, E.S., S. Selkowitz, V. Bazjanac, V. Inkarojrit, C. Kohler. 2002. High-Performance Commercial Building Façades. LBNL-50502, Lawrence Berkeley National Laboratory, Berkeley, CA. 
16. Lee, E.S., S.E. Selkowitz, R.D. Clear, D.L. DiBartolomeo, J.H. Klems, L.L. Fernandes, G.J. Ward, V. Inkarojrit, M. Yazdanian. 2006. A Design Guide for Early-Market Electrochromic Windows. California Energy Commission, PIER. 500-01-023. LBNL59950.

17. Summary of Technology Transfer Activities: Journal articles, conference papers, popular press, and presentations, including copies of articles.

Other LBNL technical reports on electrochromic windows are available at:

http://btech.lbl.gov/pub/papers.html

Search for title: electrochromics.

\section{References}

Granqvist, C.G. 2000. Electrochromic Tungsten Oxide Films: Review of Progress 1993-1998.

Solar Energy Materials \& Solar Cells 60 (2000) 201-262.

Wienold, J. 2003. Switchable façade technology: Building integration - Final report. Report number: swift-wp3-ise-jw-030616, Fraunhofer Institute for Solar Energy Systems, Heidenhofstr. 2, D-79110 Freiburg. http://www.eu-swift.de/

Zinzi, M. 2006. "Office worker preferences of electrochromic windows: a pilot study", Building and Environment, in press, 2006. 


\section{Appendix: Curtainwall Details for an Electrochromic Window Wall}

Attached are curtainwall details developed by Wausau Window and Wall Systems for the LBNL Windows Test Facility. 


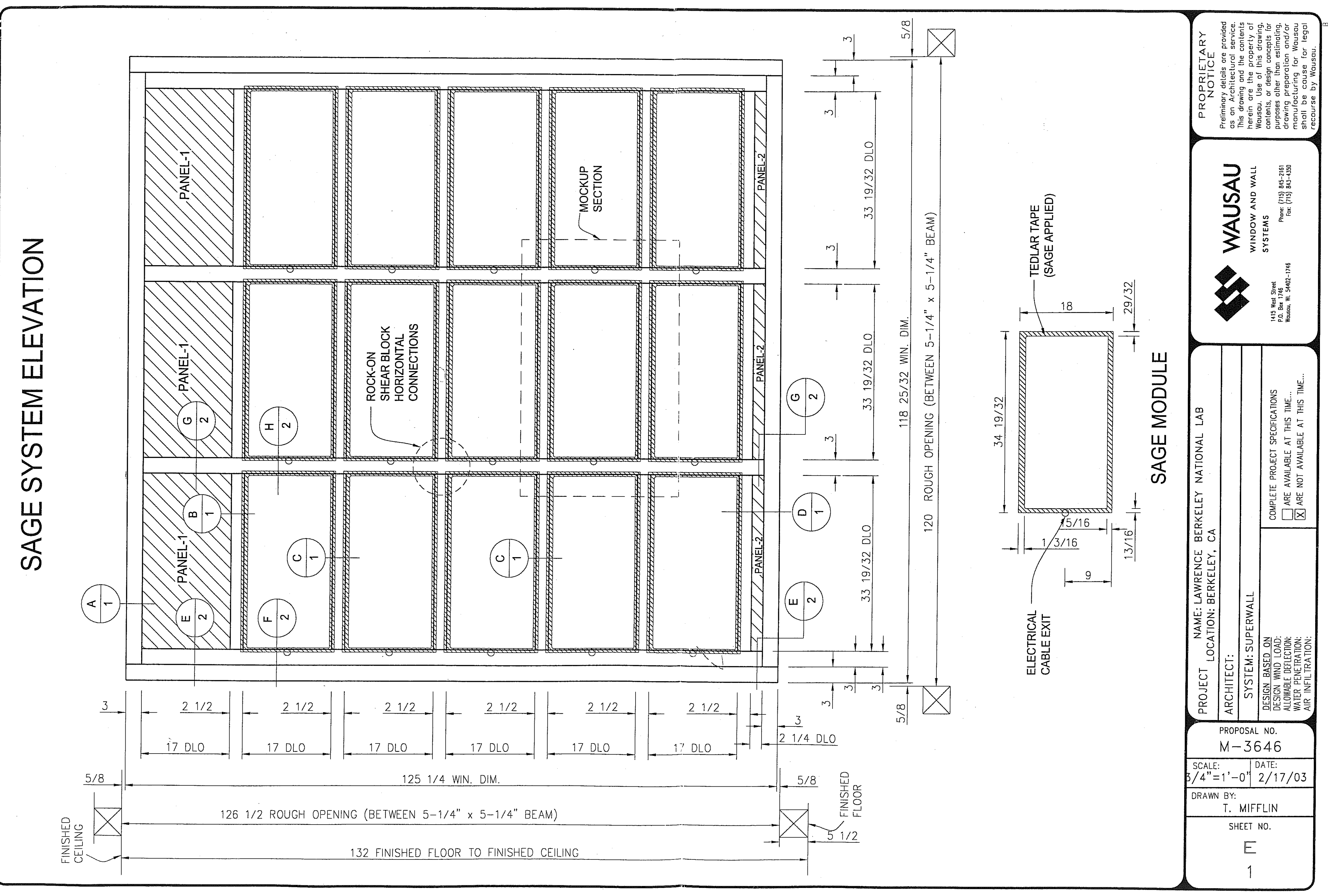



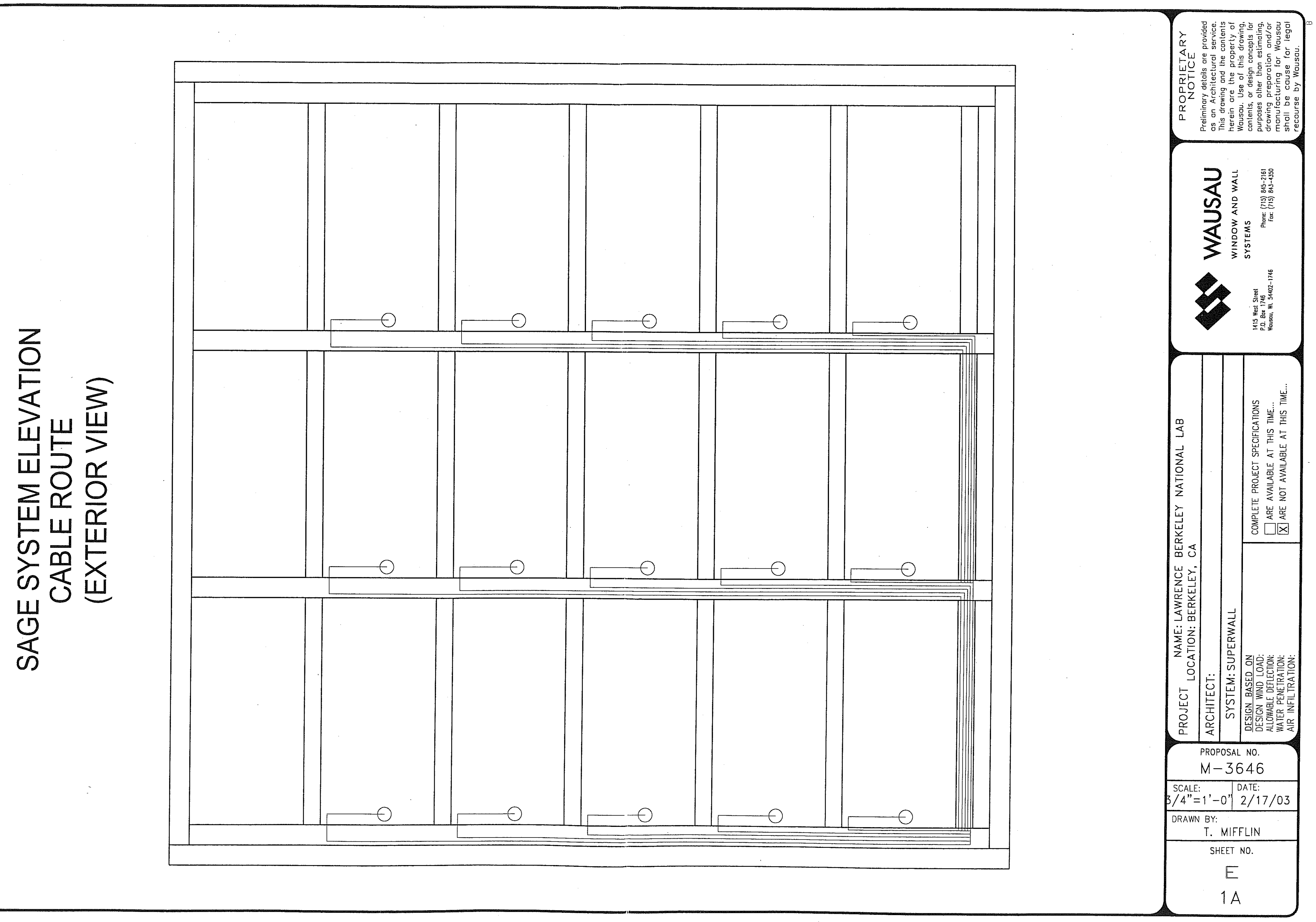


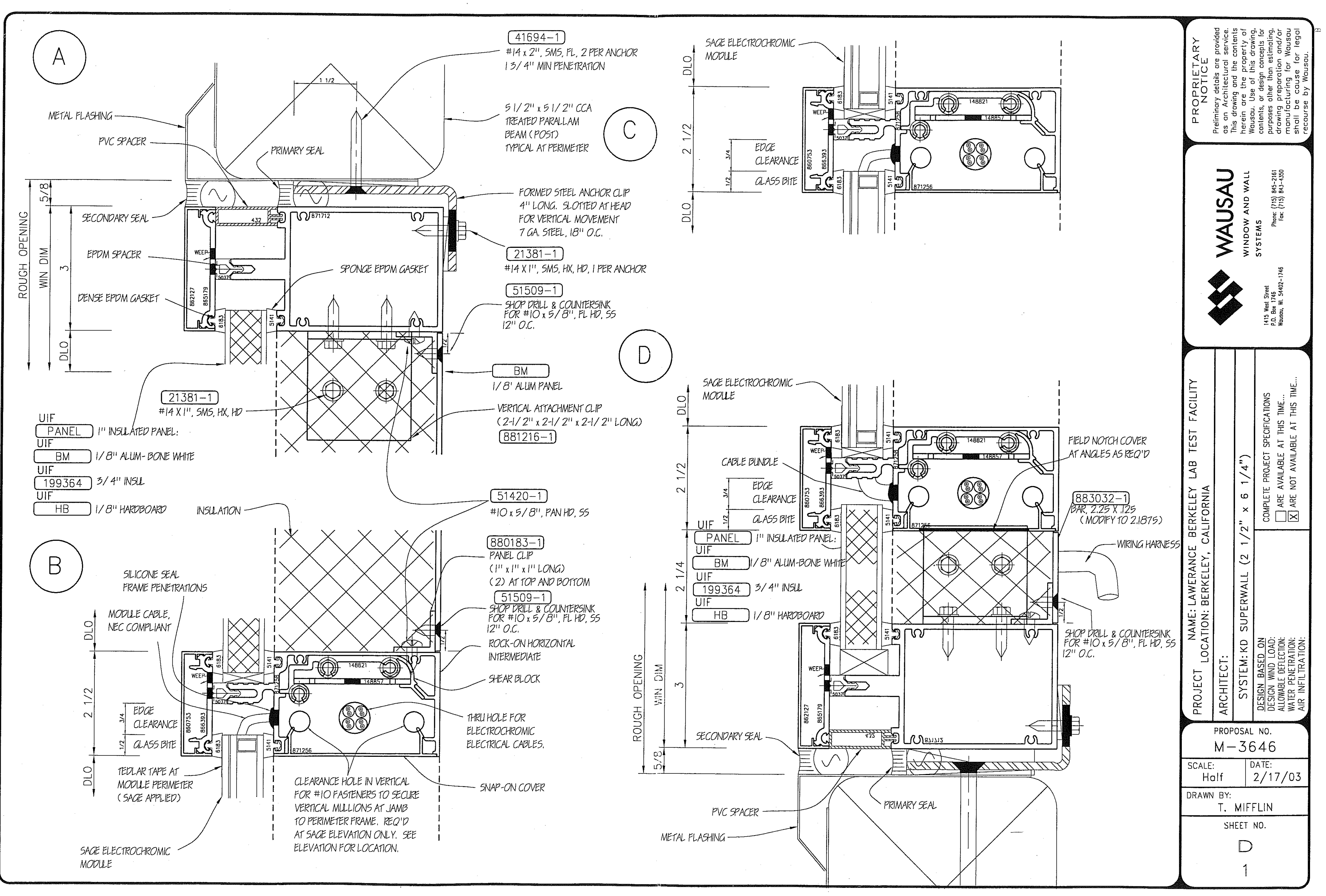



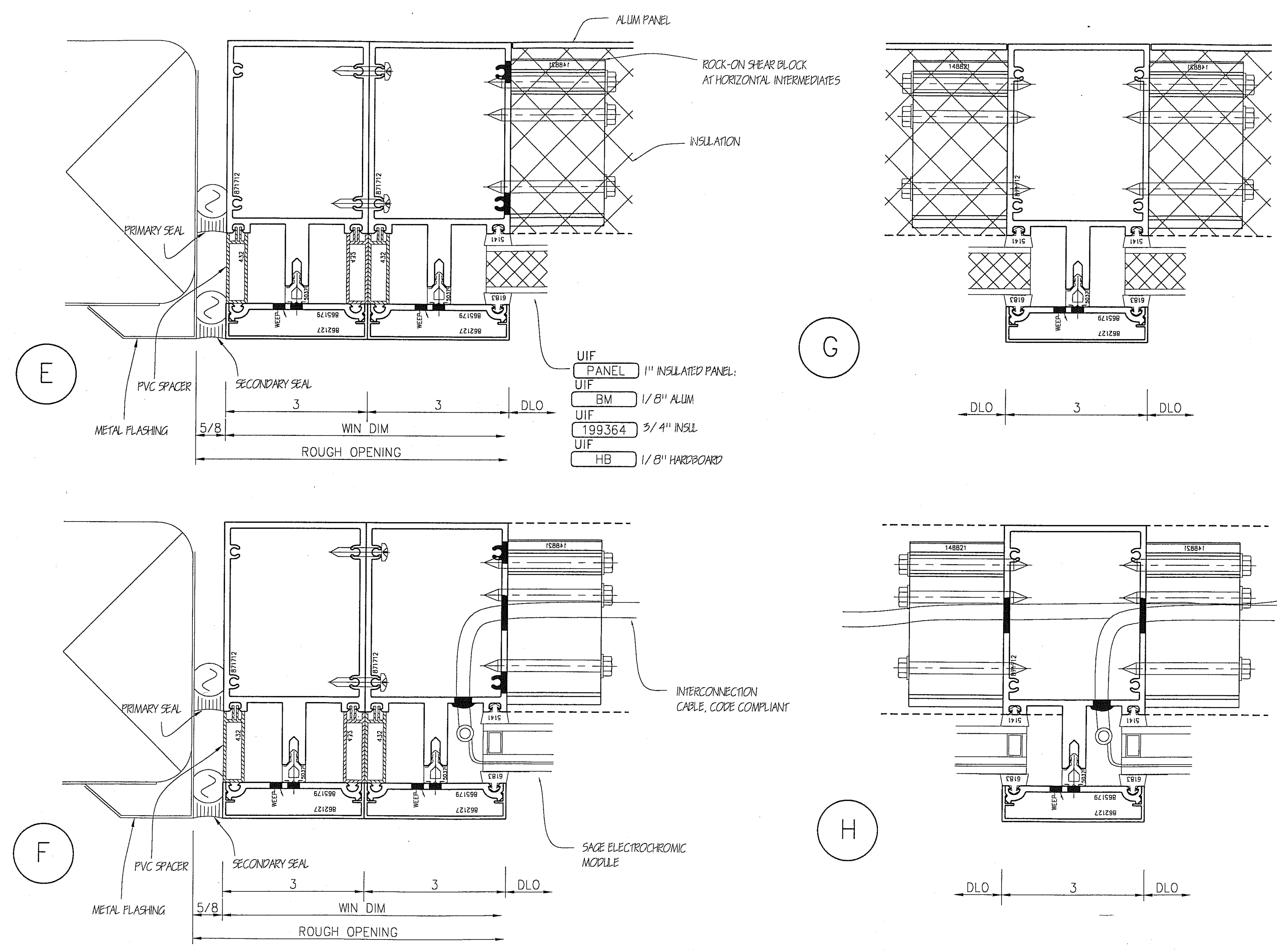

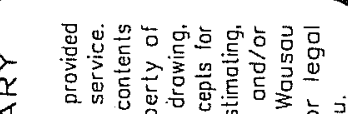

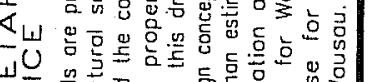

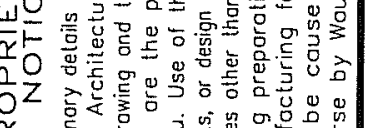

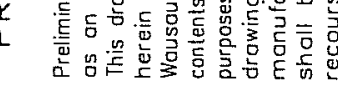

家琵

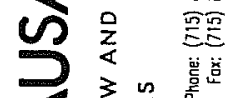
III

. BM $1 / 8^{\prime \prime}$ ALUM 199364 3/4" NSW HB I/ B" HARLBOARD

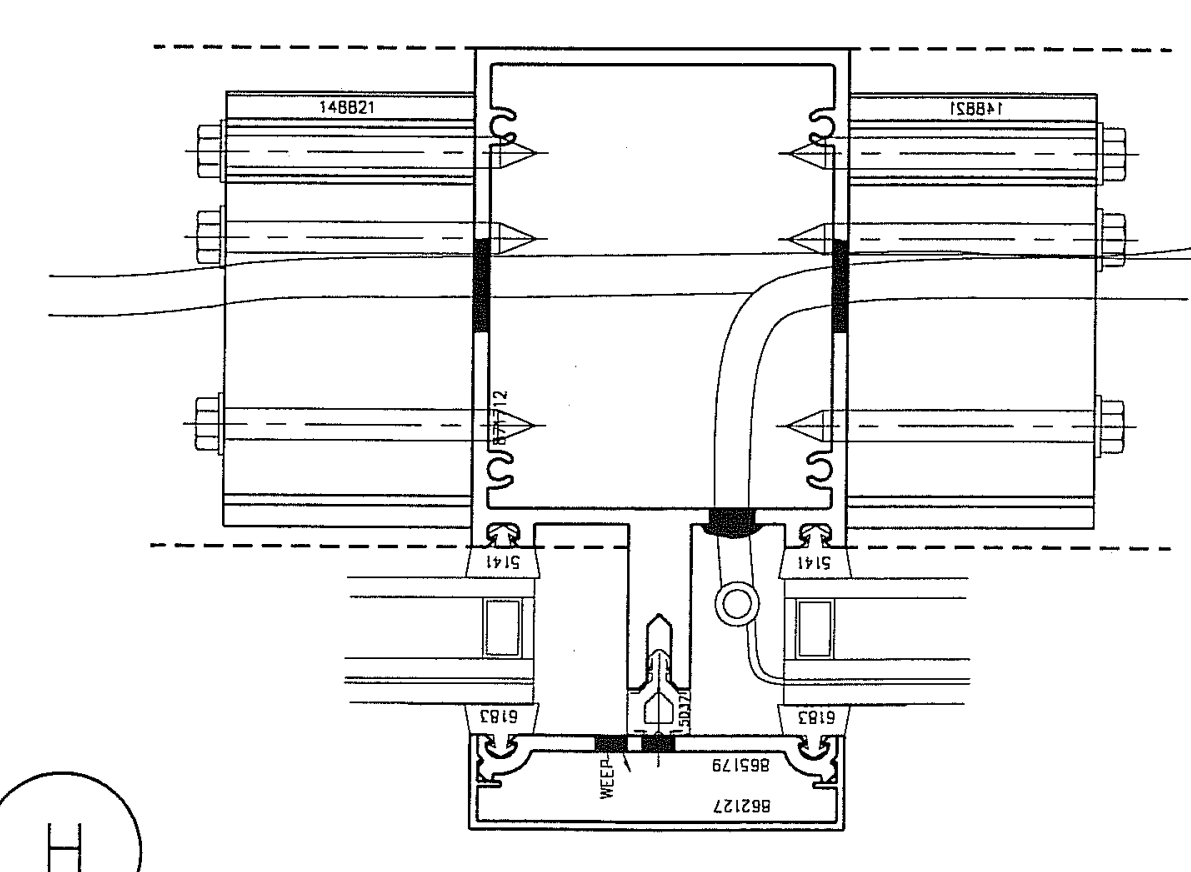

(H)
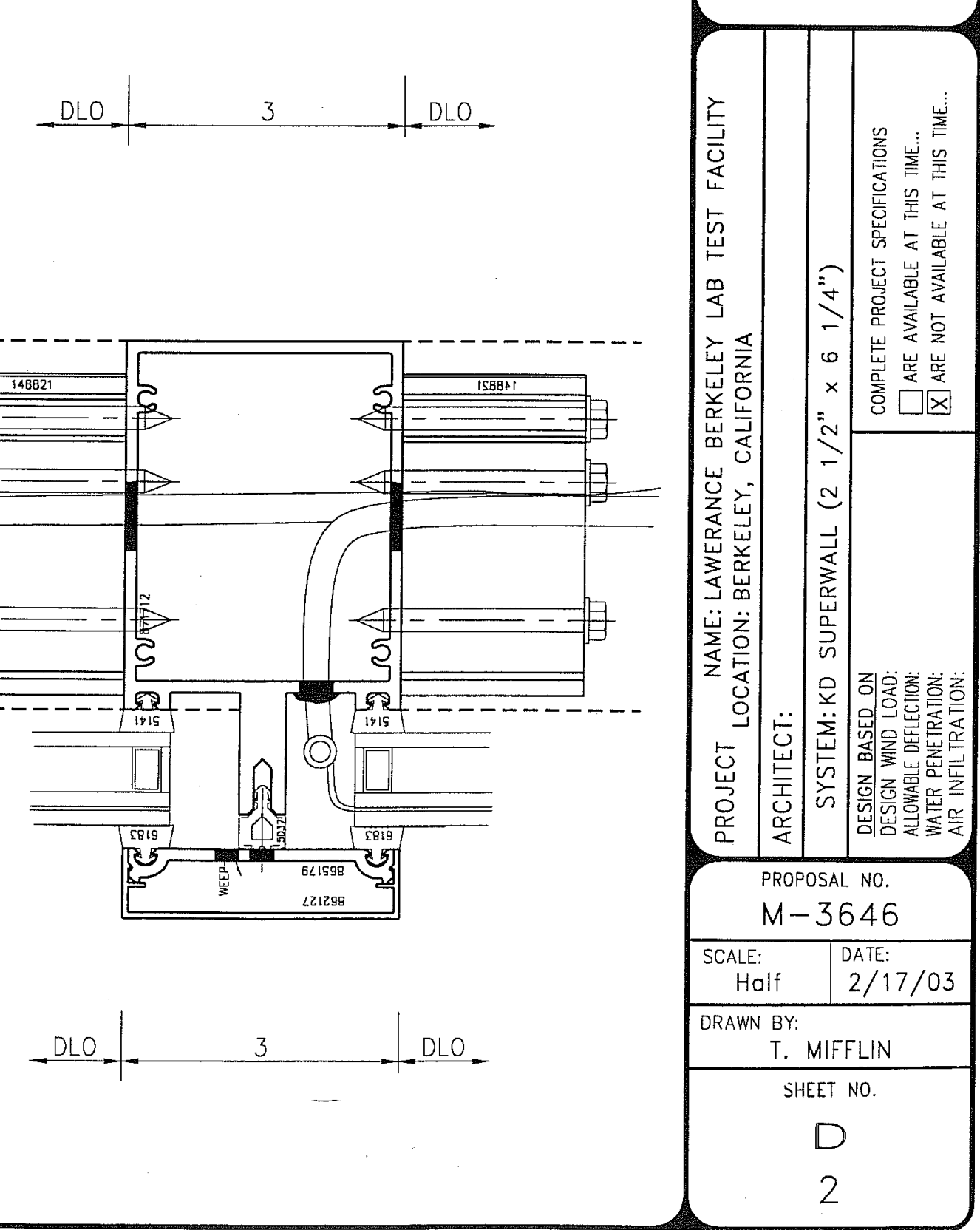


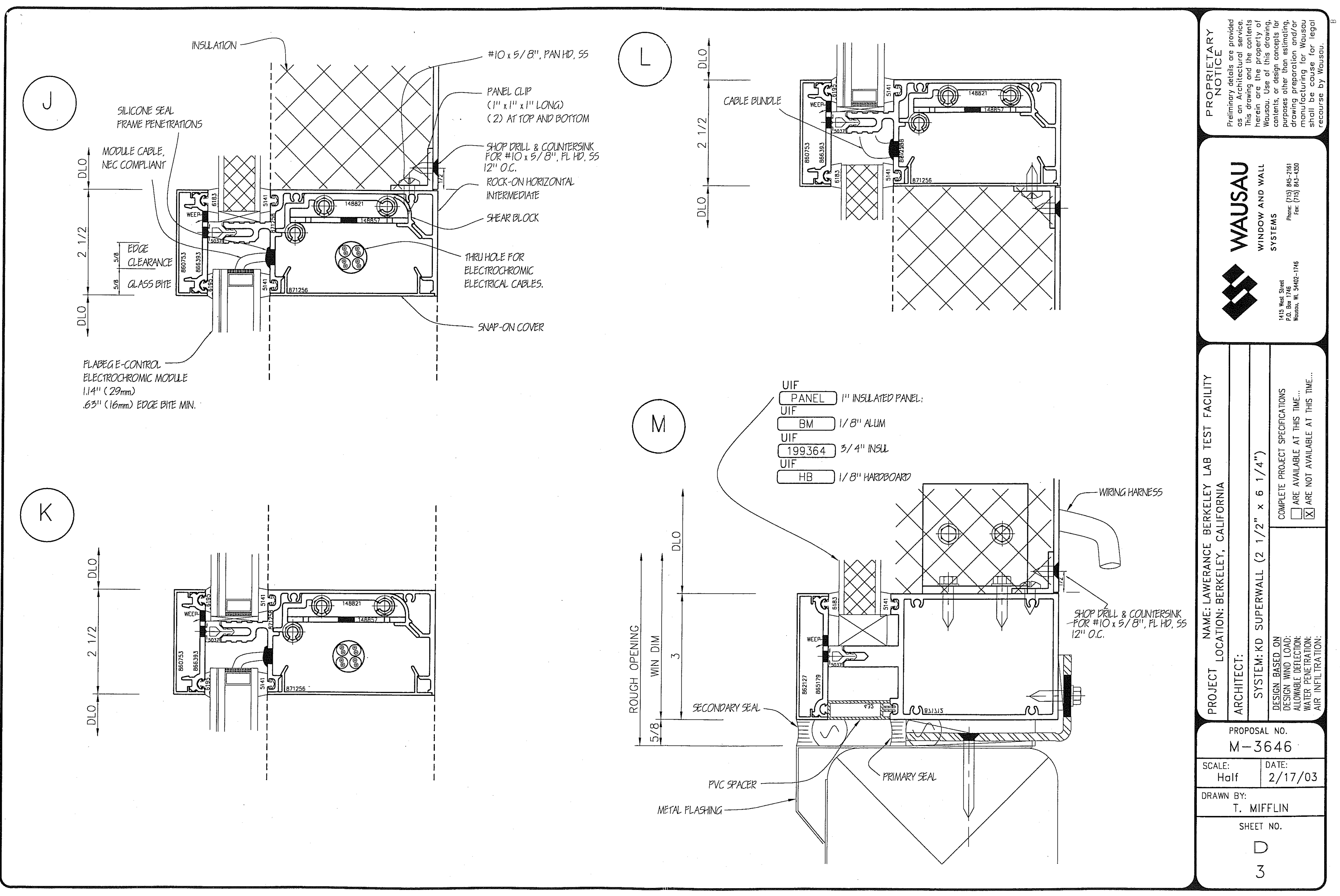




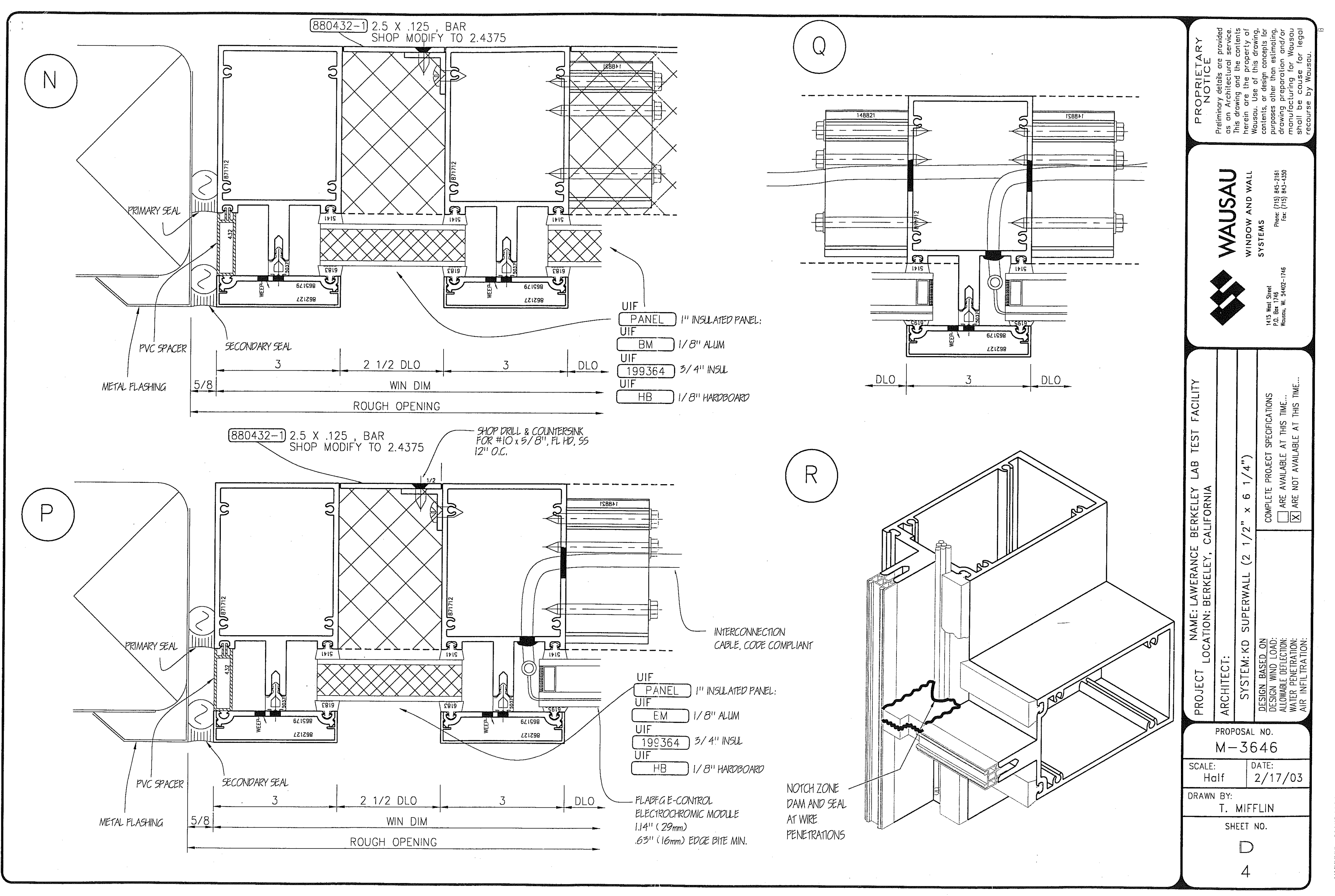

